\title{
TMIST-2 Transport Test
}

\author{
Glen R. Longhurst
}

February 2008

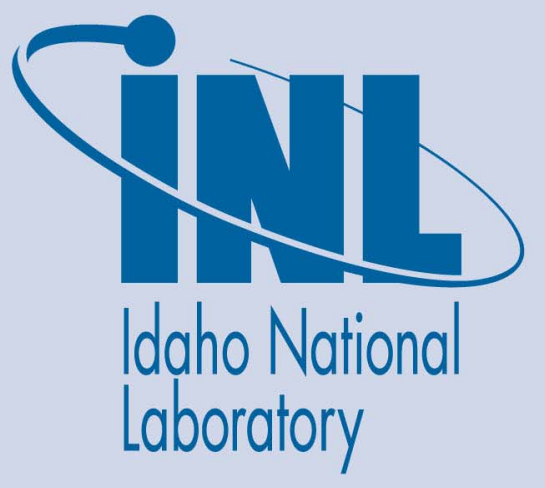

The INL is a U.S. Department of Energy National Laboratory operated by Battelle Energy Alliance 
INL/EXT-08-13791

\section{TMIST-2 Transport Test}

Glen R. Longhurst

February 2008

\section{Idaho National Laboratory \\ Fuels and Materials Performance Department Idaho Falls, Idaho 83415}

Prepared for the

U.S. Department of Energy

Office of National Nuclear Security Administration

Under DOE Idaho Operations Office

Contract DE-AC07-05ID14517 


\section{DISCLAIMER}

This information was prepared as an account of work sponsored by an agency of the U.S. Government. Neither the U.S. Government nor any agency thereof, nor any of their employees, makes any warranty, expressed or implied, or assumes any legal liability or responsibility for the accuracy, completeness, or usefulness, of any information, apparatus, product, or process disclosed, or represents that its use would not infringe privately owned rights. References herein to any specific commercial product, process, or service by trade name, trade mark, manufacturer, or otherwise, does not necessarily constitute or imply its endorsement, recommendation, or favoring by the U.S. Government or any agency thereof. The views and opinions of authors expressed herein do not necessarily state or reflect those of the U.S. Government or any agency thereof. 



\begin{abstract}
In anticipation of the TMIST-2 experiment in the Advanced Test Reactor, there was a need to determine if the tritium that is expected to be observed at the outlet of the experiment would be seen or if it may be lost on its way from the experiment in the core to the measurement station. To assist in resolving that issue, a bench-scale experiment was conducted in the Idaho National Laboratory's Safety and Tritium Applied Research (STAR) facility using deuterium and a mass spectrometer in lieu of tritium with ion chambers, bubblers, and scintillation counting. The experiment replicated the concentration of the hydrogen isotope, the flow rates anticipated, and the residence times. It was found that there is initial conversion of deuterium to water with uptake on tubing walls, but that saturates relatively quickly, and once saturated, the concentration of deuterium at the outlet of the tubing system is essentially the same as it is at the experiment inlet under the conditions modeled in the experiment.
\end{abstract}




\section{CONTENTS}

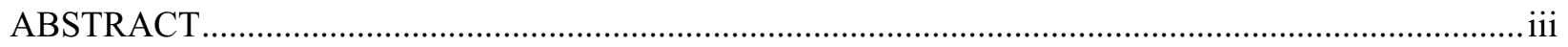

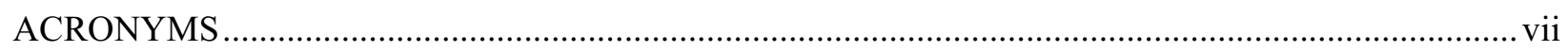

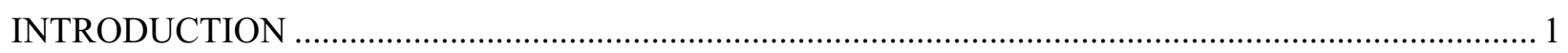

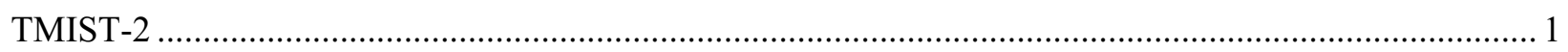

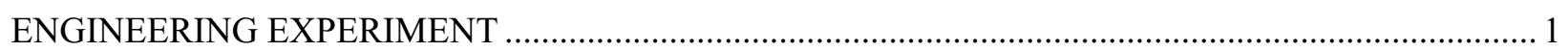

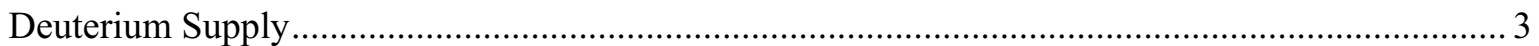

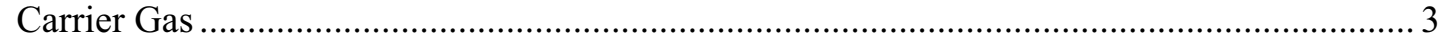

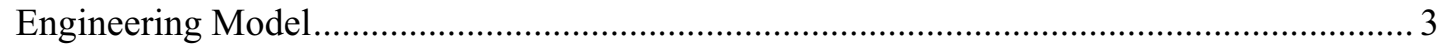

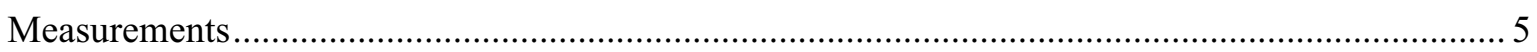

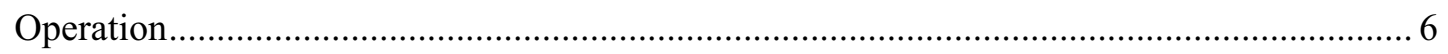

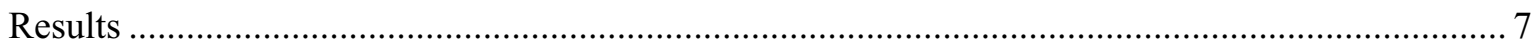

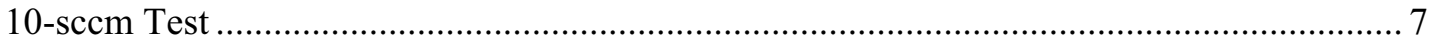

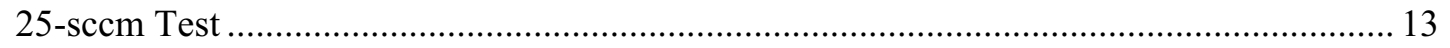

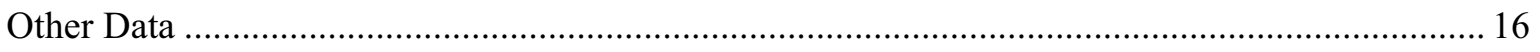

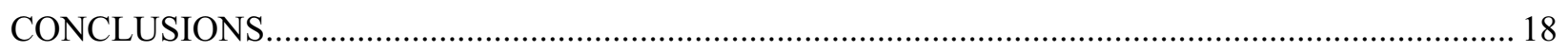

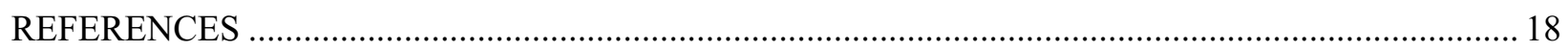

FIGURES

Figure 1. General configuration of TMIST-2 experiment capsule. ....................................................... 1

Figure 2. Elements of the TMIST-2 Tritium Supply and Measurement System......................................2

Figure 3. Configuration of the TMIST-2 engineering experiment......................................................... 3

Figure 4. Engineering model of the TMIST-2 capsule showing the stainless steel tube representing the capsule in the center and the two coil segments of copper tubing. The transition tube, beginning at bottom right center, is mostly hidden under insulation................... 5

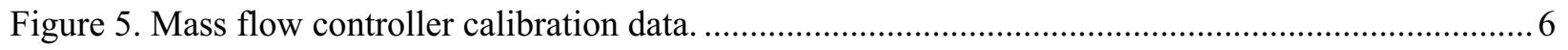

Figure 6. Duct connections to mass spectrometer.............................................................................. 7

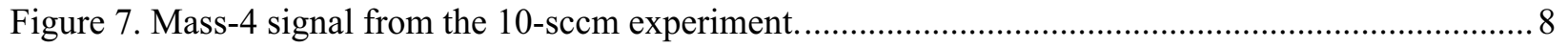

Figure 8. Comparison of inlet peak from Figure 7 with amplified and time-dilated outlet peak................ 9

Figure $9 . D_{2}$ spike comparison for experiment with only the copper tubing using the same scaling

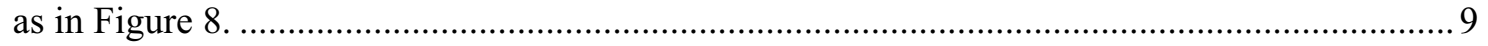

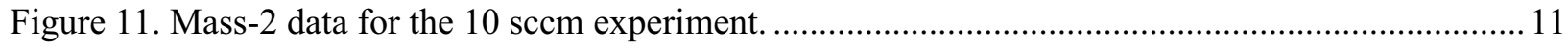

Figure 12. Mass-19 data for the 10 -sccm experiment........................................................................ 12

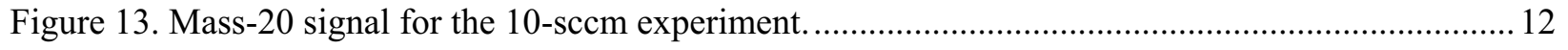

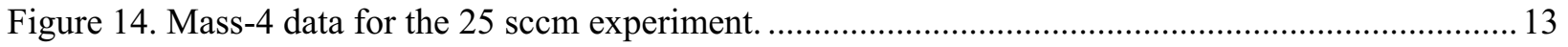


Figure 15. Mass-3 data from the 25 -sccm experiment...................................................................... 14

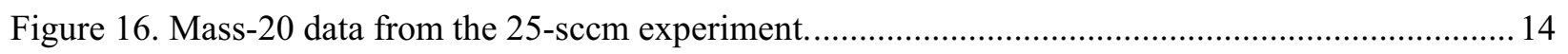

Figure 17. Mass- 19 data from the 25 -sccm experiment.................................................................... 15

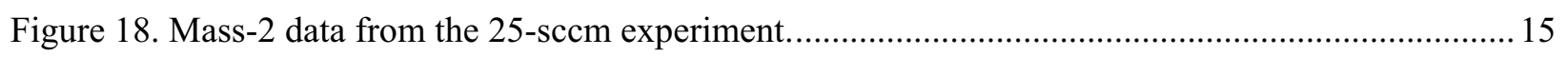

Figure 19. Test data for $\mathrm{D}_{2}$ in an 80 -ft long 1/8-inch stainless steel tube with the carrier gas

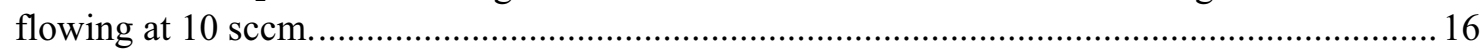

Figure 20. Arrhenius plot of the rate coefficient expressed by Equation (3) ......................................... 17 


\section{ACRONYMS}

$\begin{array}{ll}\text { ATR } & \text { Advanced Test Reactor } \\ \text { INL } & \text { Idaho National Laboratory } \\ \text { MFC } & \text { mass flow controller } \\ \text { psia } & \text { pounds per square inch absolute } \\ \text { psid } & \text { pounds per square inch differential } \\ \text { psig } & \text { pounds per square inch gauge } \\ \text { sccm } & \text { standard cubic centimeters per minute } \\ \text { STAR } & \text { Safety and Tritium Applied Research Laboratory } \\ \text { TMIST } & \text { TPBAR Materials Irradiation Separate-Effects Tests } \\ \text { TPBAR } & \text { Tritium Producing Burnable Absorber Rod }\end{array}$




\section{INTRODUCTION}

The TMIST-2 experiment ${ }^{1,2}$ will explore tritium permeation through stainless steel liners of the Tritium Producing Burnable Absorber Rods (TPBAR). Low levels of tritium are expected to diffuse through that component and be carried by gases used for controlling experiment temperature to ion chambers and bubblers for subsequent scintillation counting. Because of observations in prior experiments, ${ }^{3}$ there has been a question as to whether or not the tritium permeating into the gas stream would be clearly observable at the point of observation. To assist in resolving that question, an engineering model test was conducted at the Idaho National Laboratory (INL). This report documents the results of that experiment.

\section{TMIST-2}

The TMIST-2 experiment will consist of 4 capsules assembled into a test train that will be placed in the B2 test position of the Advanced Test Reactor (ATR). Figure 1 shows the general arrangement of a capsule while Figure 2 depicts the general arrangement of the Tritium Supply and Measurement System that will be used to furnish $\mathrm{T}_{2}$-laden $\mathrm{He}$ supply gas and measure the tritium in the carrier gas returning from the experiment.

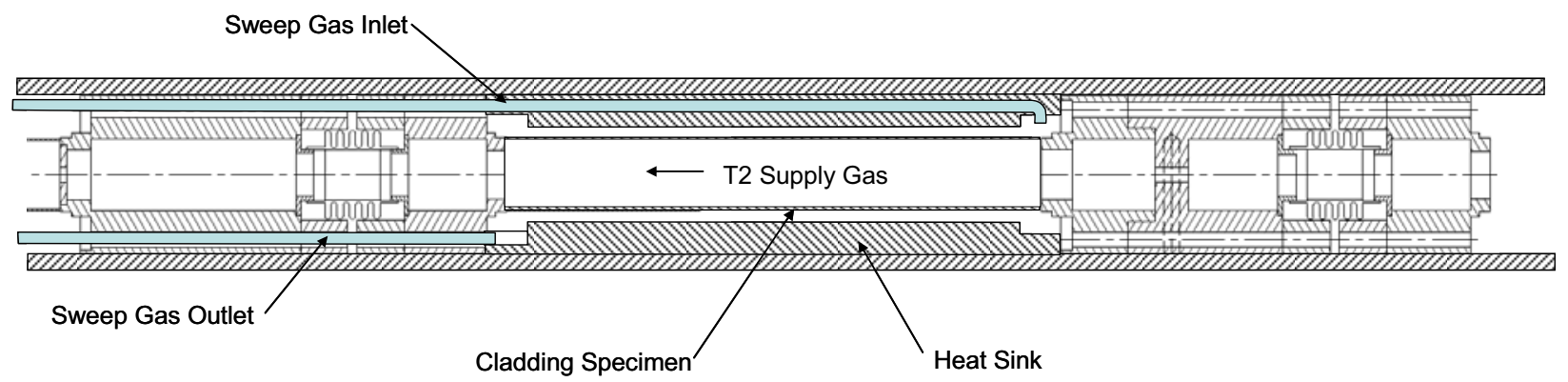

Figure 1. General configuration of TMIST-2 experiment capsule.

Tritium as $\mathrm{T}_{2}$ will be introduced at the bottom of the column of capsules and then flowed up through the center channel where it will be in contact with the inside of all the cladding specimens, the inner surfaces of the bulkhead assemblies between capsules, and the bellows. Sweep gas, a mixture of He and Ne that will be used for experiment temperature control, will be introduced at the bottom (right in Figure 1) of each of the four capsules independently and collected at the top of each capsule chamber. Inlet and outlet tubes will be Type 316L stainless steel. The outlet tubes will continue to about 1 foot above the top of the reactor core where, inside the lead-out assembly, they will transition to copper that will carry the sweep gas to the measurement system in the 1B cubicle. The inlet and outlet tubes in the experiment assembly will be 1/16-inch stainless steel. The copper tube going to the cubicle will be 1/8-inch.

\section{ENGINEERING EXPERIMENT}

An engineering experiment was set up in the Safety and Tritium Applied Research (STAR) facility at the INL. The objective of the experiment was to assemble and test a performance analog of the capsule and transport system to explore the extent to which tritium may be lost in TMIST-2, using deuterium as a surrogate for tritium.

The configuration of that experiment is shown in Figure 3. The mass spectrometer is an Ametek Proline working under Dycor 2000 software. It has 8 ports of which only 5 are used, as shown in Figure 3. These may be opened only by the software, one at a time. Mass flow controllers (MFCs) are Teledyne Hastings 


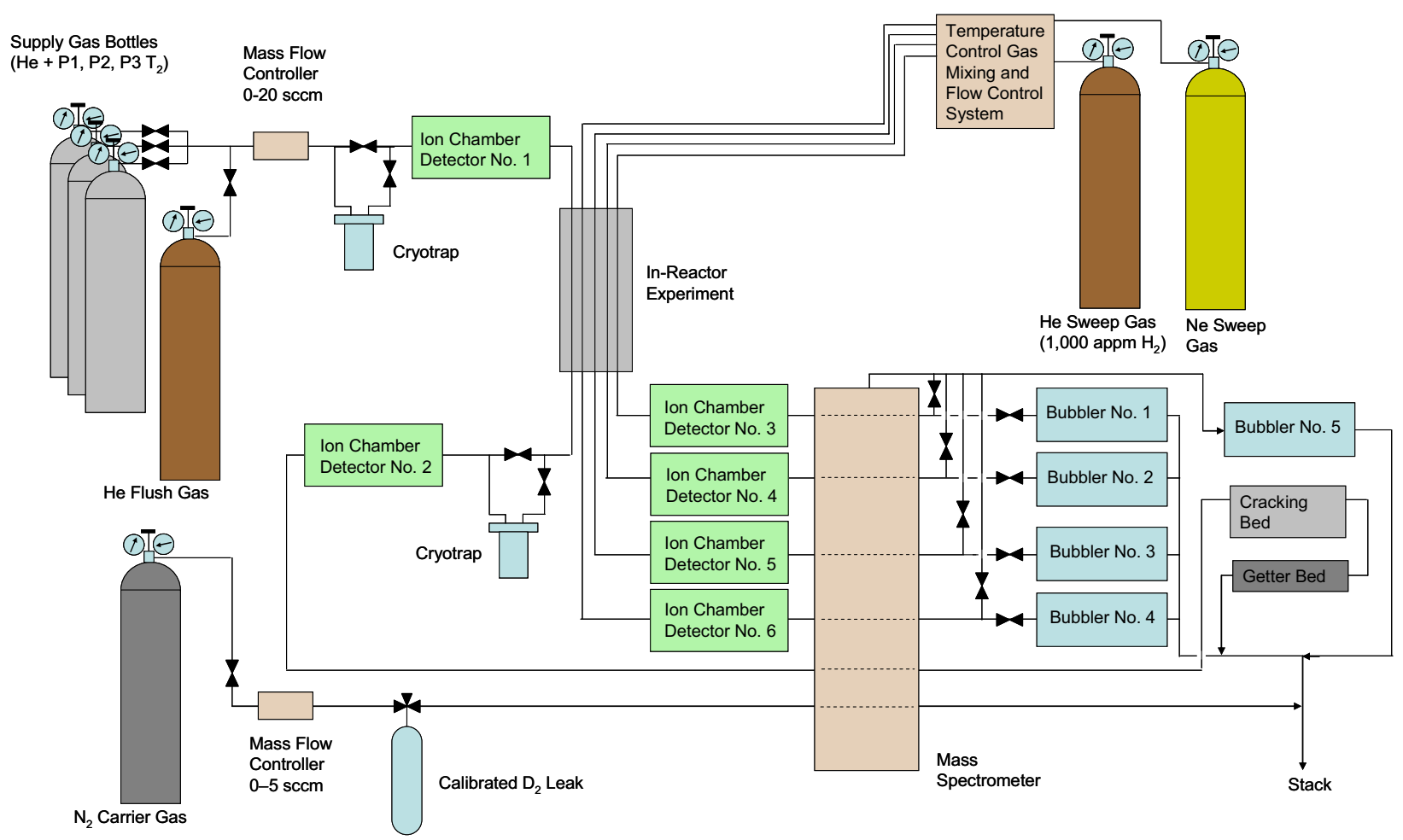

Figure 2. Elements of the TMIST-2 Tritium Supply and Measurement System.

HFC-302 units operated from National Instruments LabView software through an SCXI-1124 module with an SCXI-1325 terminal block. LabView also records data from the MFC commands and responses and the differential pressure transducer, all operating in the 4-20 mA mode, and 3 Type-K thermocouples ( 2 shown plus ambient air temperature) using an SCXI-1102 module with an SCXI-1325 terminal block. The modules connect to a PC through an SCXI-1000 chassis, an SCXI 1349 adapter, an SHC68-68-EPM data cable, and a NI PCI 6251 multi-function M-series data acquisition card. LabView also gathers data on the mass spectrometer quadropole mass peak currents and port valve open state data from the Dycor 2000 software, which is operating on the same computer.

The deuterium leak was calibrated at $1.65 \mathrm{E}-05 \mathrm{sccm}$ into atmospheric pressure gas, leaking $\mathrm{N}_{2}-10 \% \mathrm{D}_{2}$, so that when valve V1 is open, the $\mathrm{D}_{2}$ rate to the experiment circuit is $1.65 \mathrm{E}-06 \mathrm{sccm}$. Valve V11 is a Swagelok BM stainless steel metering valve. Working in combination with V5 (1/3 psid Swagelok check valve) it allows splitting of the $\mathrm{D}_{2}$ current from the leak. V3 is a precision pressure regulator which can be used with the nearby 100 -sccm rotameter (M1) to allow high-speed purging of the remainder of the experiment. MFC-1 is a 5-sccm mass flow controller. MFC-2 has a $20-\mathrm{sccm}$ full range. The MFCs operate at 15 psig input pressure.

The differential pressure transducer is an Omega PX771A-025DI capacitance driven unit with a full-scale pressure reading of 25 psid, operating in the $4-20 \mathrm{~mA}$ mode. All check valves are 1/3 psi Swagelok check valves. All other valves are Swagelok BN bellows-sealed stainless steel gate valves. The oxidizer bed contains copper turnings that have been oxidized in air at $450^{\circ} \mathrm{C}$. The temperature of the oxidizer bed is typically $370^{\circ} \mathrm{C}$ when operating.

We now consider in greater detail the design and sizing of specific parts of the engineering experiment. 


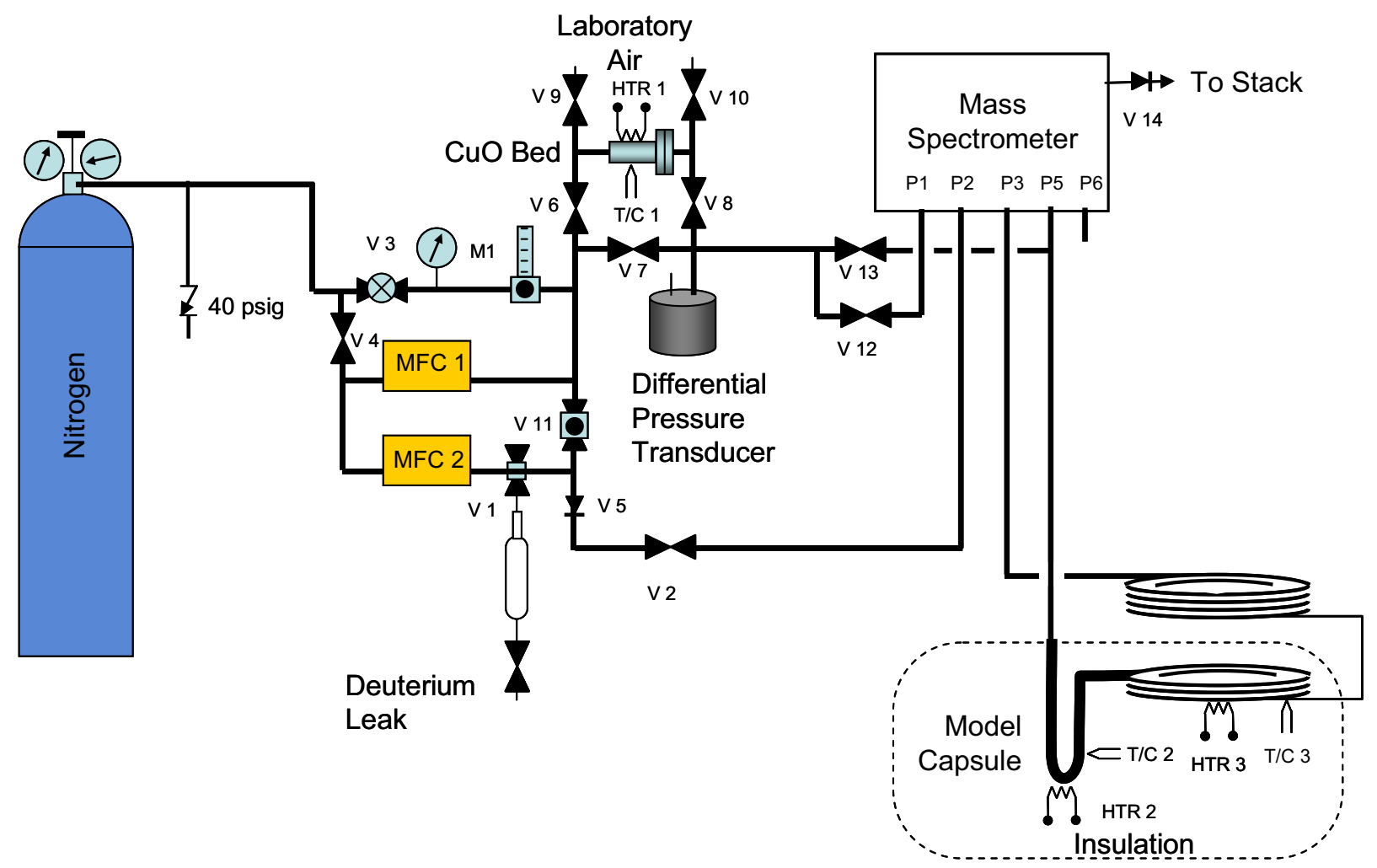

Figure 3. Configuration of the TMIST-2 engineering experiment.

\section{Deuterium Supply}

In TMIST-2, the permeating current of tritium is expected to be in the range of $10^{7}$ to $10^{12}$ tritium atoms per second. While some of the emerging tritium will oxidize to become HTO, most will become HT or $\mathrm{T}_{2}$ molecules. In the engineering experiment of Figure 3 where deuterium is used as a surrogate for tritium, deuterium was supplied as $\mathrm{D}_{2}$ gas from the calibrated leak. The deuterium current when the leak valve was opened was $1.67 \mathrm{E}-6 \mathrm{sccm}$ or $4.49 \mathrm{E}+13 \mathrm{D}_{2} / \mathrm{s}$. This was a little above the upper end of the expected range in TMIST-2, but it was clearly visible on the mass spectrometer at carrier gas flows used in these experiments. By dividing the flow from the calibrated leak using the valve assembly (opening V2 and adjusting V11) it was possible to reduce that deuterium current to the experiment.

\section{Carrier Gas}

The sweep gas in TMIST-2 will pick up permeated tritium at the experiment capsule and carry it to a measurement station. It will be a He-Ne mixture. Because He has the same atomic mass as the $\mathrm{D}_{2}$ molecule, it is not possible to distinguish $\mathrm{D}_{2}$ from $\mathrm{He}$ in the mass spectrometer. Likewise, because we are interested in water molecules with mass $20, \mathrm{Ar}$ is not a suitable carrier at mass 40 because Ar doubly ionized in the quadropole would appear to have mass 20 . Ne at mass 20 is also a problem. We resorted to $\mathrm{N}_{2}$ in the engineering experiment because it does not mask signals we are interested in, and its chemical reactivity with the metals is slight.

\section{Engineering Model}

The TMIST-2 experiment has effectively three components involved with transporting the permeating tritium to the measurement station. First is the capsule surrounding the cladding test specimen, through which the sweep gas passes and where it picks up tritium that has permeated through the cladding test 
specimen. Next is the stainless steel tubing that carries the sweep gas to a point above the reactor core where the transition to copper is made, and finally, there is the copper tube that goes to the cubicle. Modeling of these components is now considered.

\section{Capsule}

The TMIST-2 experiment has four separate capsules, A, B, C, and D, each slightly different from the others. Capsule $\mathrm{C}$ was chosen for modeling in this experiment. From detailed drawings and dimensions of the TMIST-2 capsules, it was found that the volume exposed to the sweep gas in capsule $\mathrm{C}$ is $0.558 \mathrm{in}^{3}$. The surface area of the heat sink exposed to the flowing gas is $11.08 \mathrm{in}^{2}$. The wetted area of the B-C bulkhead is $3.416 \mathrm{in}^{2}$ and the wetted area of the C-D bulkhead is $2.004 \mathrm{in}^{2}$. Taking half of the bulkhead areas as being associated with capsule $\mathrm{C}$, the total area exposed to the sweep gas in the capsule to which tritium may be lost is $13.79 \mathrm{in}^{2}$. This does not count the area of the cladding specimen, since it is the source of the tritium.

Two parameters were modeled in the engineering experiment: residence time and the surface-to-volume ratio. When both of these are matched, the time the sweep gas takes to pass through the capsule will be replicated, and the loss rate, which takes place on the surfaces, will also be replicated. The surface-tovolume ratio for the capsule was found from

$$
\frac{S}{V}=\frac{13.79 \mathrm{in}^{2}}{0.558 \mathrm{in}^{3}}=24.71 \mathrm{in}^{-1}
$$

The capsule can be represented by a length of Type 316L stainless steel tubing. Noting that the surface-tovolume ratio is $2 / R$, where $R$ is the radius of a tube, it was found from (1) that a tube with an inside diameter of 0.182 inches would provide an excellent model. There was available $1 / 4$-inch $316 \mathrm{~L}$ stainless steel tubing with wall thickness $0.035 \mathrm{inch}$, which has an inside diameter of $0.180 \mathrm{inch}$, almost exactly what was sought. It was found further that 21.9 inches of this tubing were required to have an interior volume of $0.558 \mathrm{in}^{3}$. With the simplifying supposition that the tritium will permeate the liner test specimen more or less uniformly over its length, it was supposed this would be equivalent to a point source half way down the capsule. Hence, the engineering model of the capsule was made only 11 inches long.

\section{Transition Tube}

The $\mathrm{C}$ capsule will be located just below the reactor mid-plane, so the top of the capsule will be very near the mid-plane. The distance from the capsule to the point of transition to the copper tubing was estimated to be approximately 36 inches. The interior volume of a 36 -inch length of 1/16-inch tubing with $0.014-$ inch walls is $0.0337 \mathrm{in}^{3}$. For robustness and convenience, this element was modeled not with 1/16-inch tube but with 1/8-inch tube. For the same interior volume, giving the same residence time, the length of the $1 / 8$-inch tube was made to be 9 inches.

\section{Copper Duct}

From the top of the transition point above the core to the top head of the reactor will be approximately 20 feet. From the top head of the reactor to the location of the instrumentation in the $1 \mathrm{~B}$ cubicle was estimated to be between 60 and 80 feet. It was chosen to represent this combined length of copper duct with a 100 -foot long coil of $1 / 8$-inch copper tubing.

Figure 4 shows the assembled model. 


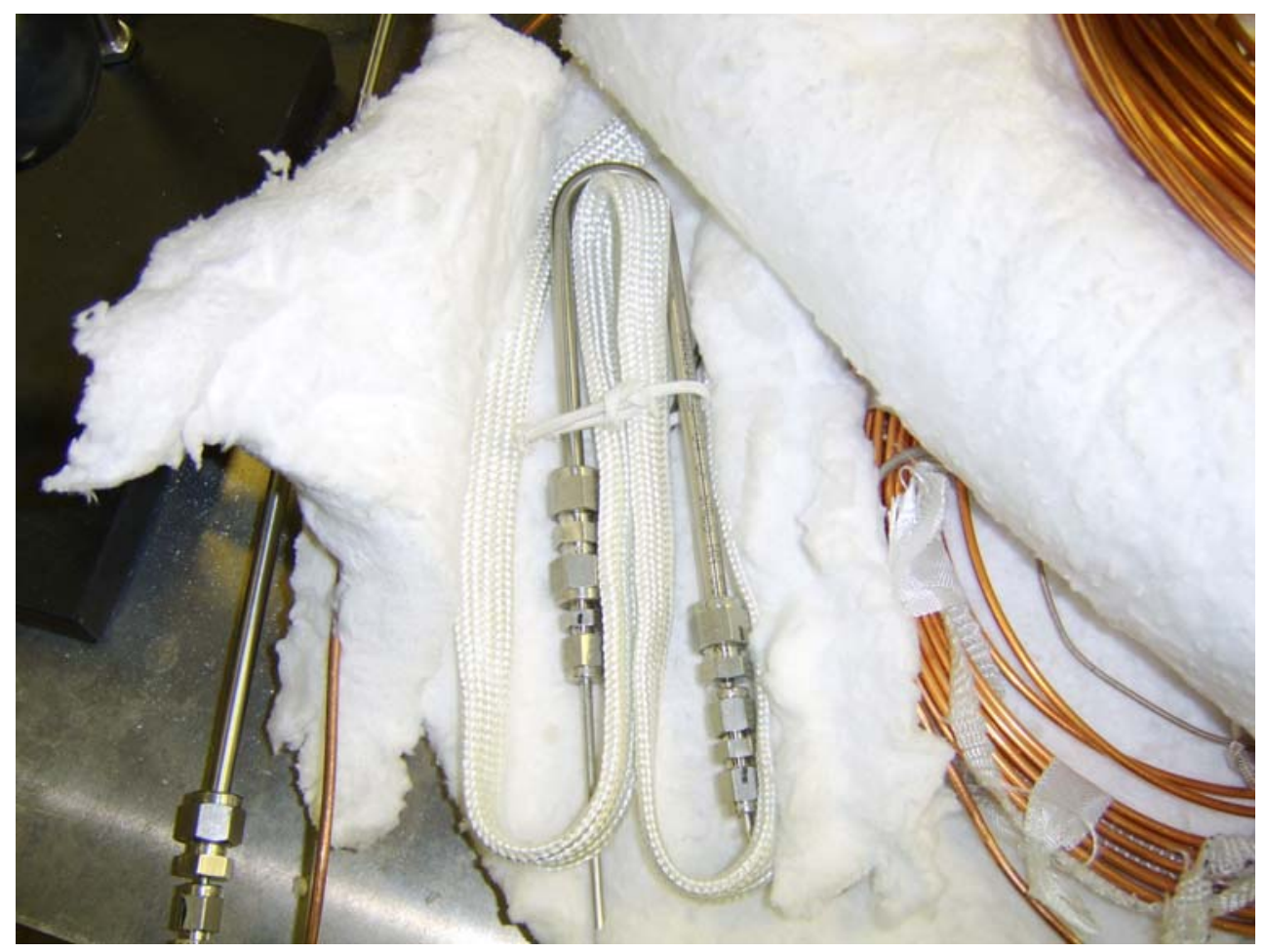

Figure 4. Engineering model of the TMIST-2 capsule showing the stainless steel tube representing the capsule in the center and the two coil segments of copper tubing. The transition tube, beginning at bottom right center, is mostly hidden under insulation.

These temperatures were achieved in the engineering model by separately locating the model capsule, the transition tube, and approximately the first 20 feet of the copper tubing inside of an insulating blanket, top and bottom. Insulation separated the components inside the blanket, and separate heaters and thermocouples were placed on the model capsule and on the first $20 \mathrm{ft}$ of the coil, as shown in Figure 4. The remainder of the copper tubing was in the laboratory room atmosphere, on top of the insulation, as suggested in Figure 3 and shown in Figure 4. Manual adjustment of the rheostats controlling the heaters was used to maintain the temperatures to within $2^{\circ} \mathrm{C}$ of the desired temperatures during the experiments.

\section{Gas Flow Rates}

The expected mass flow rate of the sweep gas through the TMIST-2 capsules will be approximately 10 to $30 \mathrm{sccm}$. For the engineering experiment, flow rates of $25 \mathrm{sccm}$ and $10 \mathrm{sccm}$ were selected. The $25-\mathrm{sccm}$ rate is the maximum attainable in the experiment with the existing mass flow controllers, and it is close to the upper rate expected in TMIST-2. Erring on the low side for flow rate is conservative in that the longer the gas spends in contact with the tubing walls, the more tritium may be expected to leave or react. The 10 -sccm rate is the more probable one. It provided a gas mixture richer in $\mathrm{D}_{2}$ when mixing with the constant source rate from the calibrated leak. It provided a more clearly discernable signal from the mass spectrometer.

\section{Measurements}

The mass spectrometer was the principal diagnostic instrument in this experiment. With accurate mass flows and the calibrated leak, there was confidence in the $\mathrm{D}_{2}$ concentration going into the experiment. 


\section{Calibration}

Mass flows from the two mass flow controllers were calibrated using a positive gas displacement bubble tube and found to be linear. The actual mass flow from MFC-2 was found to be about $2.8 \%$ higher than the indicated flow (Figure 5). The $\mathrm{D}_{2}$ concentration was used to calibrate the mass spectrometer for mass 4 and, with a conversion factor of the square root of the mass ratio, for masses 2 and 3 . The calibration factor for $\mathrm{D}_{2}$ was $7.69 \mathrm{E}+14 \mathrm{ppb} / \mathrm{A}$. For masses 3 and 2, the factors were $6.66 \mathrm{E}+14$ and $3.84 \mathrm{E}+14 \mathrm{ppb} / \mathrm{A}$, respectively

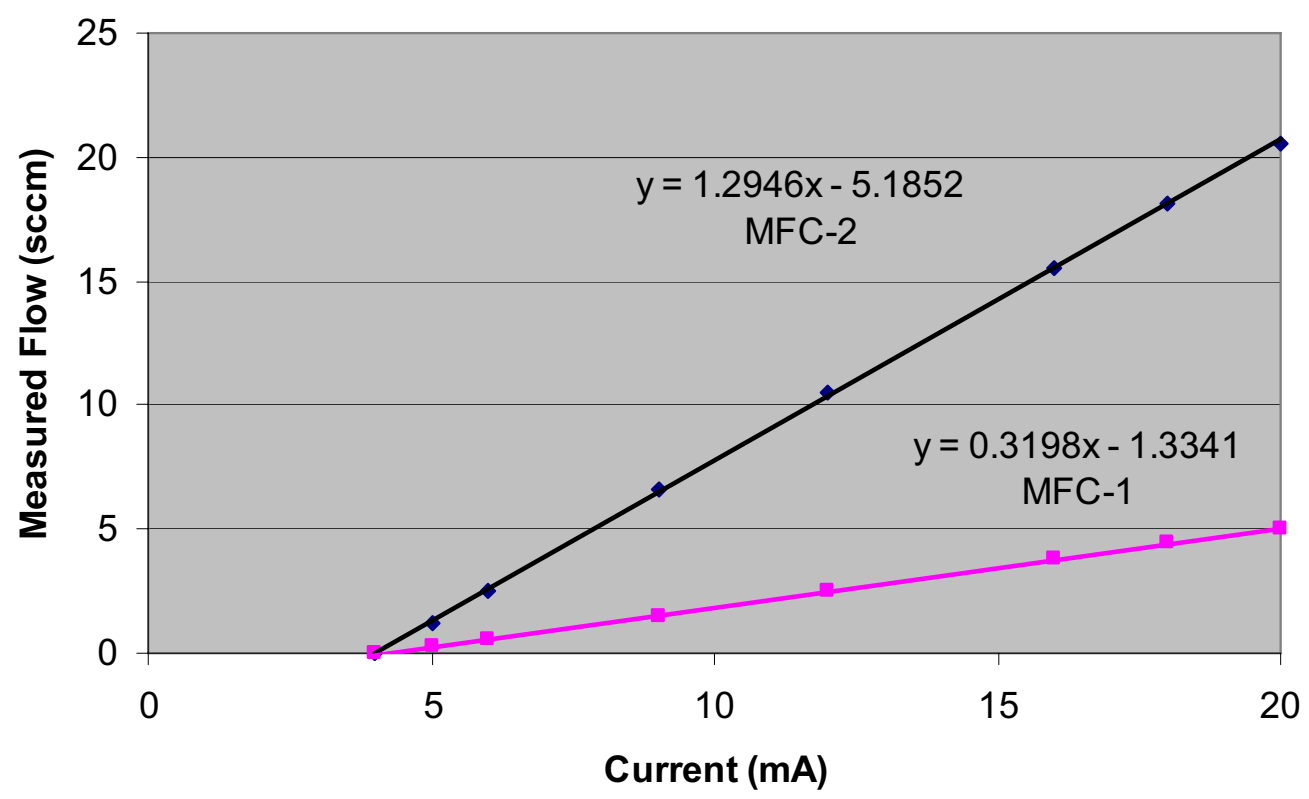

Figure 5. Mass flow controller calibration data.

Calibration for water species was achieved by measuring room air for which the water concentration was known from a GE Panametrics MMS 35 ceramic cell hygrometer. On the day of the test, the dew point of room air was $52.5^{\circ} \mathrm{F}\left(11.37^{\circ} \mathrm{C}\right)$, so for a local atmospheric pressure of 12.38 psia, the water concentration in the air was $1.576 \%$. The calibration factor for water was found to be $7.54 \mathrm{E}+13 \mathrm{ppm} / \mathrm{A}$.

\section{Operation}

By sampling the $\mathrm{N}_{2}$ carrier gas as it went into the engineering model and again as it came out, looking at mass 4 and others of interest, it was possible to obtain the primary data needed from this experiment.

An explanation needs to be made regarding the way in which the mass spectrometer operates to properly understand the results. The mass spectrometer has an inlet manifold that consists of a series of eight 3way valves (see Figure 6). Unless a given gas line is actually being sampled, the flow through the mass spectrometer "IN" port goes directly through the valve assembly and back through the "OUT" port to the stream or manifold or it remains stagnant if the "OUT" port is capped. When a gas line is sampled, the entire flow through that line goes past the sampling capillary and on to a common exhaust line. Therefore, in order to get a sample of the gas flowing into the experiment and still have gas going to the experiment, it was necessary to take a side stream from the main flow to the experiment for sampling by the mass spectrometer. The fraction of the total stream that went through the mass spectrometer was controlled by valves in the exhaust stream. Measurements of the flow when sampling through port 5 in which the flow 


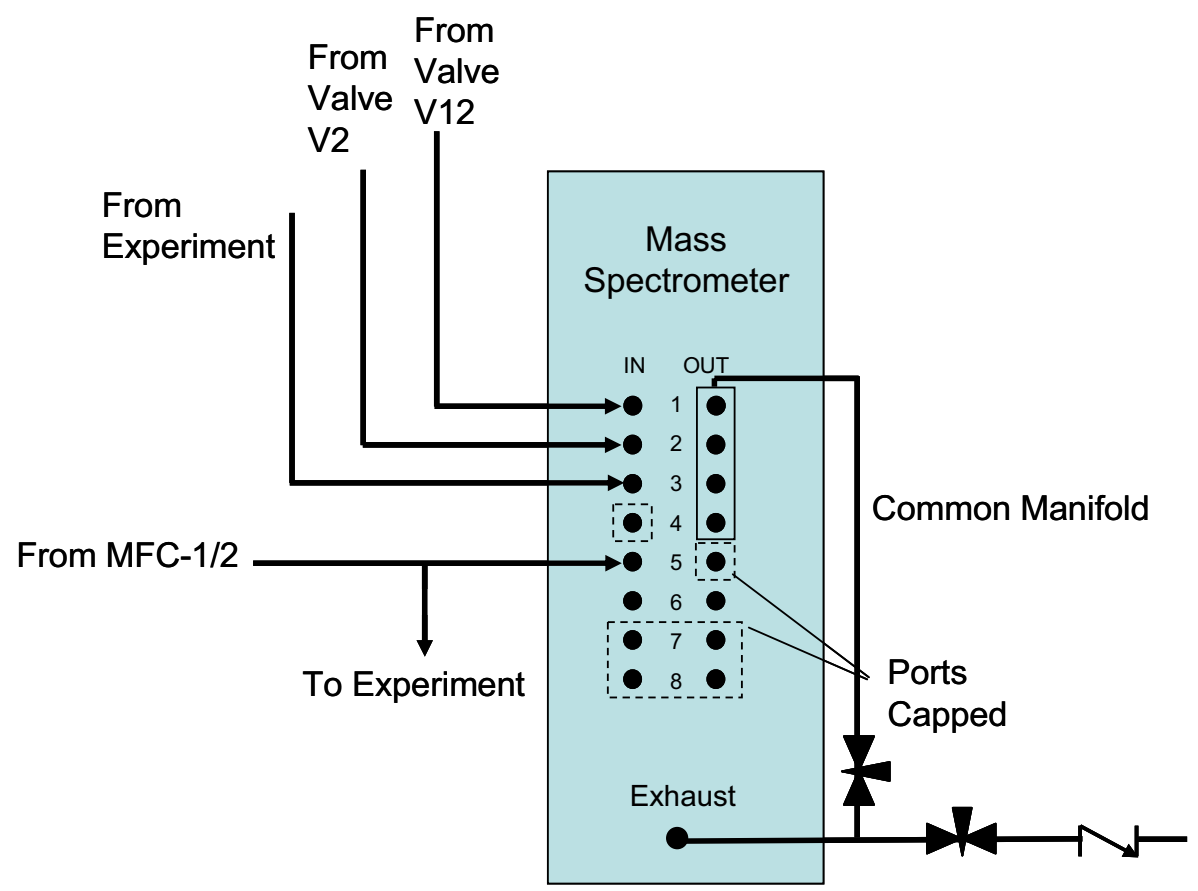

Figure 6. Duct connections to mass spectrometer

through MFC-1 was adjusted to give the same differential pressure across the experiment as the flow from MFC-2 alone, without the side stream being sampled, have shown that the reduction in flow to the experiment when mass spectrometer port 5 is opened was approximately $45 \%$. In the experiments performed and reported here, it was decided not to provide the make-up flow through MFC-1 when mass spectrometer port 5 was opened because doing so would change the $\mathrm{D}_{2}$ concentration going into the experiment. It was preferable to accept the smaller flow rate when sampling through port 5 . Throttling the exhaust channel had the effect of requiring a longer time to get to an accurate reading than if the gas is passing continually past the sampling valve. The effect on observations will be shown and discussed later in this report.

\section{Results}

Two experiment series were performed, one at $10 \mathrm{sccm}$ carrier gas rate and one at $25 \mathrm{sccm}$. Only one of each of these will now be discussed, though results were similar in other trials.

\section{0-sccm Test}

Figure 7 shows the time history of the mass- 4 signal when the carrier gas flow was controlled using MFC-2 at $10.0 \mathrm{sccm}$. The concentration of $\mathrm{D}_{2}$ at the experiment inlet, corresponding to $2.14 \mathrm{E}-13 \mathrm{~A}$ is $165 \mathrm{ppb}$.

Prior to the start of the data, the stainless steel model capsule was heated to approximately $230^{\circ} \mathrm{F}\left(110^{\circ} \mathrm{C}\right)$ and held for nearly an hour with only dry $\mathrm{N}_{2}$ flowing through the experiment. Note that the initial mass-4 signal in Figure 7 is zero. By the time the $\mathrm{D}_{2}$ was turned on, the coil temperature had fallen to $214^{\circ} \mathrm{F}$ $\left(101^{\circ} \mathrm{C}\right)$, and it was $206^{\circ} \mathrm{F}\left(96.7^{\circ} \mathrm{C}\right)$ at its lowest point. 


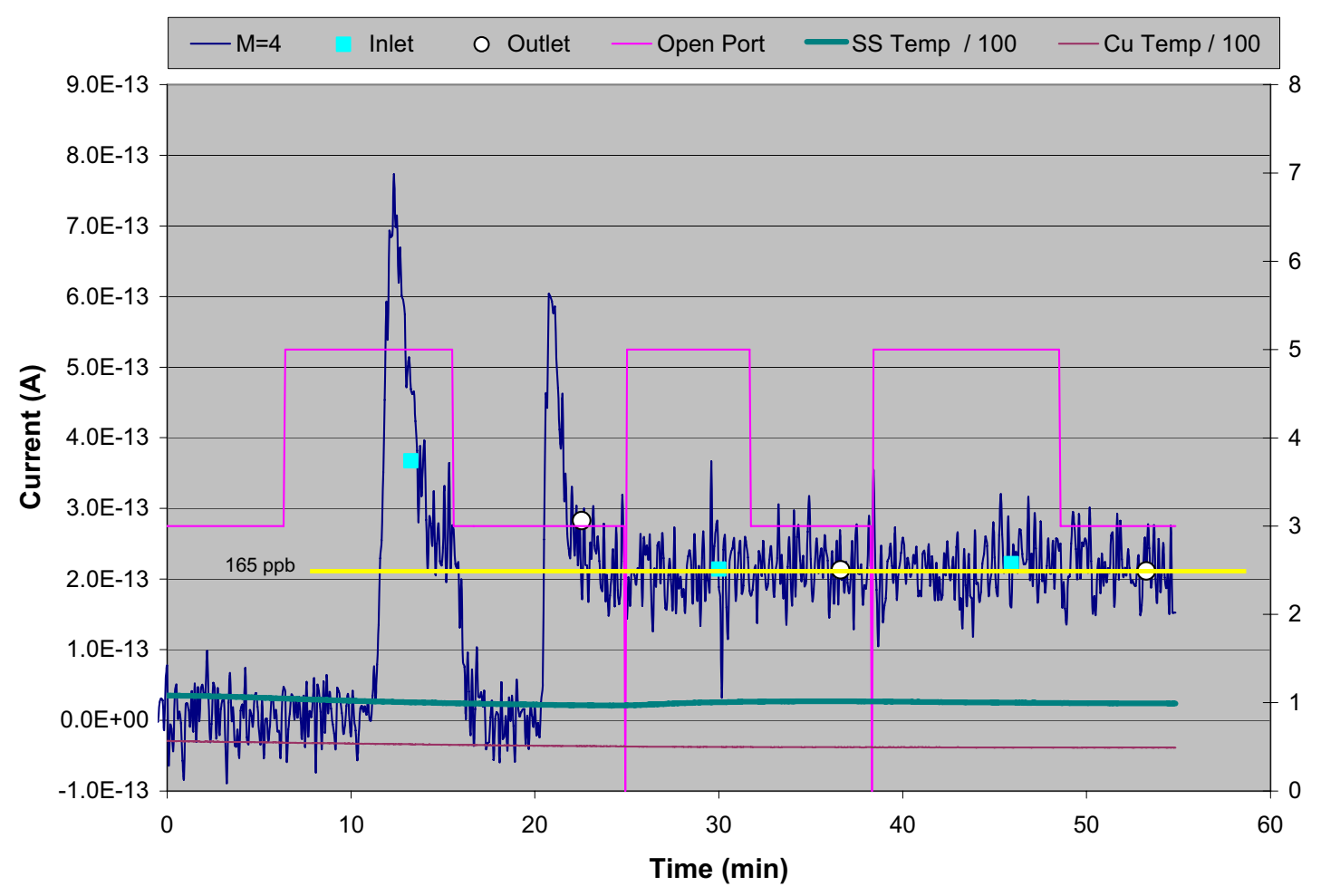

Figure 7. Mass-4 signal from the 10-sccm experiment.

Open port numbers are shown as horizontal lines in Figure 7. When the open port is 5, the mass spectrometer was sampling the gas flowing to the experiment. When the open port is 3 , the gas coming from the experiment was being analyzed.

When the valve to the calibrated leak is opened, a burst of $\mathrm{D}_{2}$ appears that has come through the capillary in the leak but that is held in by the valve until the valve is opened. This appeared as the spike at time 12.3 minutes and again at time 20.9 minutes in Figure 7. The first observation was when the burst passed the inlet to the experiment, and the second was when it emerged from the experiment. The 8.6 minutes time differential is the time required to pass through the experiment, partly at $5.47 \mathrm{sccm}$ while port 5 is opened and the remainder at $10.0 \mathrm{sccm}$ when the sampling is at port 3 . $^{\mathrm{a}}$ Note that the time width of the second spike is only about $3 / 4$ as wide as the first one, a consequence of the flow moving faster when looking through port 3 . With insignificant diffusion, the difference in flow rate changes only the time duration of the pulse, not its amplitude. This is illustrated in Figure 8 where the second peak has been amplified by $119 \%$ and dilated in time by a factor of 1.8. Except for noise, the two curves are nearly identical.

The significant aspect of these data is that the second spike is lower than the first by about $16 \%$. That is apparently the result of $\mathrm{D}_{2}$ loss in the experiment. That loss is mostly due to oxidation of the $\mathrm{D}_{2}$ to water and its adsorption on the walls somewhere in the model. That appears to saturate after a short time, however, because after about 25 minutes into the experiment, there is a much smaller difference in the

\footnotetext{
${ }^{a}$ The transit time of a 100-foot $1 / 8$-inch tube at $10 \mathrm{sccm}$ with an average temperature of $300 \mathrm{~K}$ and at actual absolute pressure of $12.79 \mathrm{psia}$ is 6.16 minutes. At $5.47 \mathrm{sccm}$ and $12.86 \mathrm{psia}$, the time is 14.79 minutes.
} 


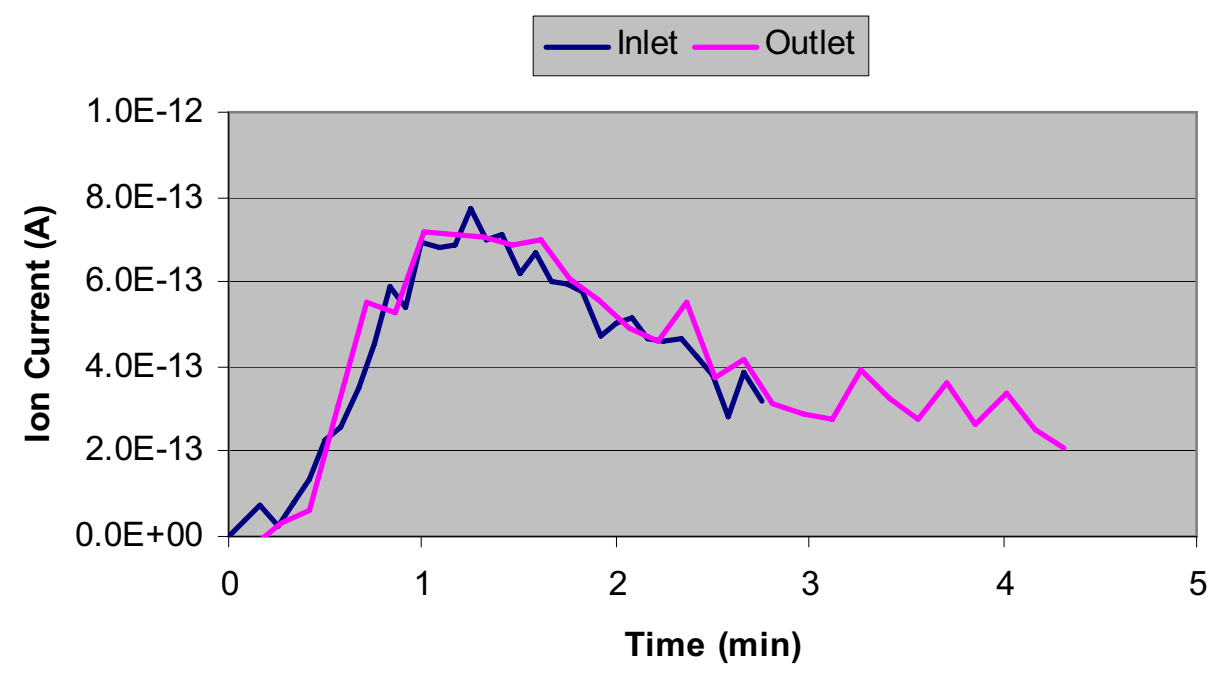

Figure 8. Comparison of inlet peak from Figure 7 with amplified and time-dilated outlet peak.

mass-4 signal between samples taken at the inlet and those taken at the outlet of the experiment. There is some hint on every inlet-outlet pair of observations that the inlet may be slightly higher than the outlet. Keeping in mind that it takes a few minutes for the mass spectrometer to reach the true reading after switching to port 5 and that some time is needed for the surface processes to equilibrate at the higher flows when switching back to port 3, the currents were averaged only over the last half of the observation period. The $\mathrm{D}_{2}$ concentration at the inlet during the period from 45 to 49 minutes is $5 \%$ greater than it is over the average after 52 minutes. The inlet value at 47 minutes appears to be the result of statistical noise because the other points are highly co-linear.

To determine where in the model the $\mathrm{D}_{2}$ was being absorbed, the experiment was repeated without the stainless steel components present, only the copper tubing. Figure 9 shows the overlay comparison using exactly the same scaling as in Figure 8.

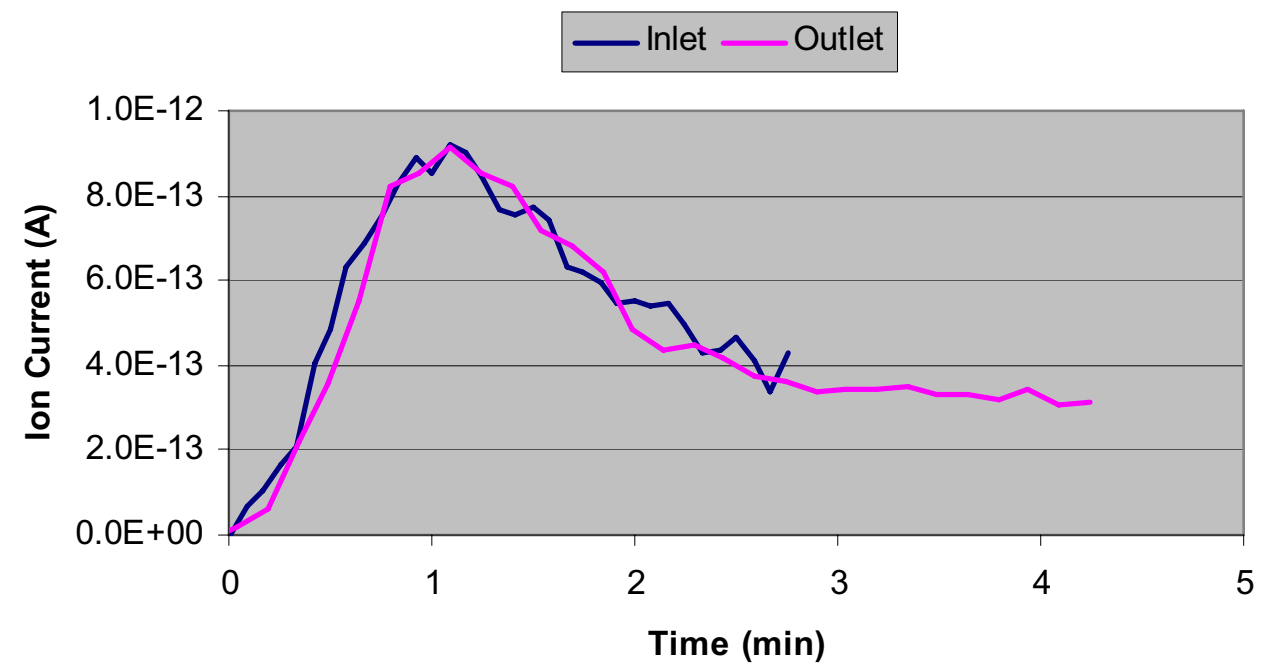

Figure $9 . \mathrm{D}_{2}$ spike comparison for experiment with only the copper tubing using the same scaling as in Figure 8. 
In comparing Figure 8 with Figure 9, the peak amplitude in Figure 9 is a little higher than that in Figure 8. That is probably because the pressure behind the leak valve in the test of Figure 9 was allowed to build longer before the valve was opened, resulting in a greater influx of $\mathrm{D}_{2}$ at valve opening, than in the test of Figure 8. The exponential decay after the peak is a little faster in Figure 9 than in Figure 8. The fact that it is the same for both curves in each figure indicates that this difference has to do with the condition of the experimental system upstream from the experiment model rather than with the presence or absence of the stainless steel capsule simulator in the experiment. Finally, the excellent overlay with the same scaling when the stainless steel components are in the experiment (Figure 8) as when it was not (Figure 9) implies that the $\mathrm{D}_{2}$ uptake during the initial time of each experiment is onto the copper surface, not onto the stainless steel.

Mass-3 data were also recorded and are shown in Figure 10. The data points give the appearance there was some HD gain in the experiment. Using the same analysis method as just described for the mass-4 data, the average values over the last half of port- 3 and port- 5 segments are compared. For the inlet-outlet pairs shown, the difference between the inlet and outlet signals ranged from 7 to $17 \%$ of the data standard deviation. This too may be simply statistical error although some small effect may be real. The outlet gas appeared to have a slightly greater HD concentration than the inlet for all inlet-outlet pairs observed. It is reasonable to think that some of the $\mathrm{D}_{2}$ entering the experiment may have been isotopically exchanging with $\mathrm{H}_{2}$ to form $\mathrm{HD}$, though this may have taken place only in the quadropole detector.

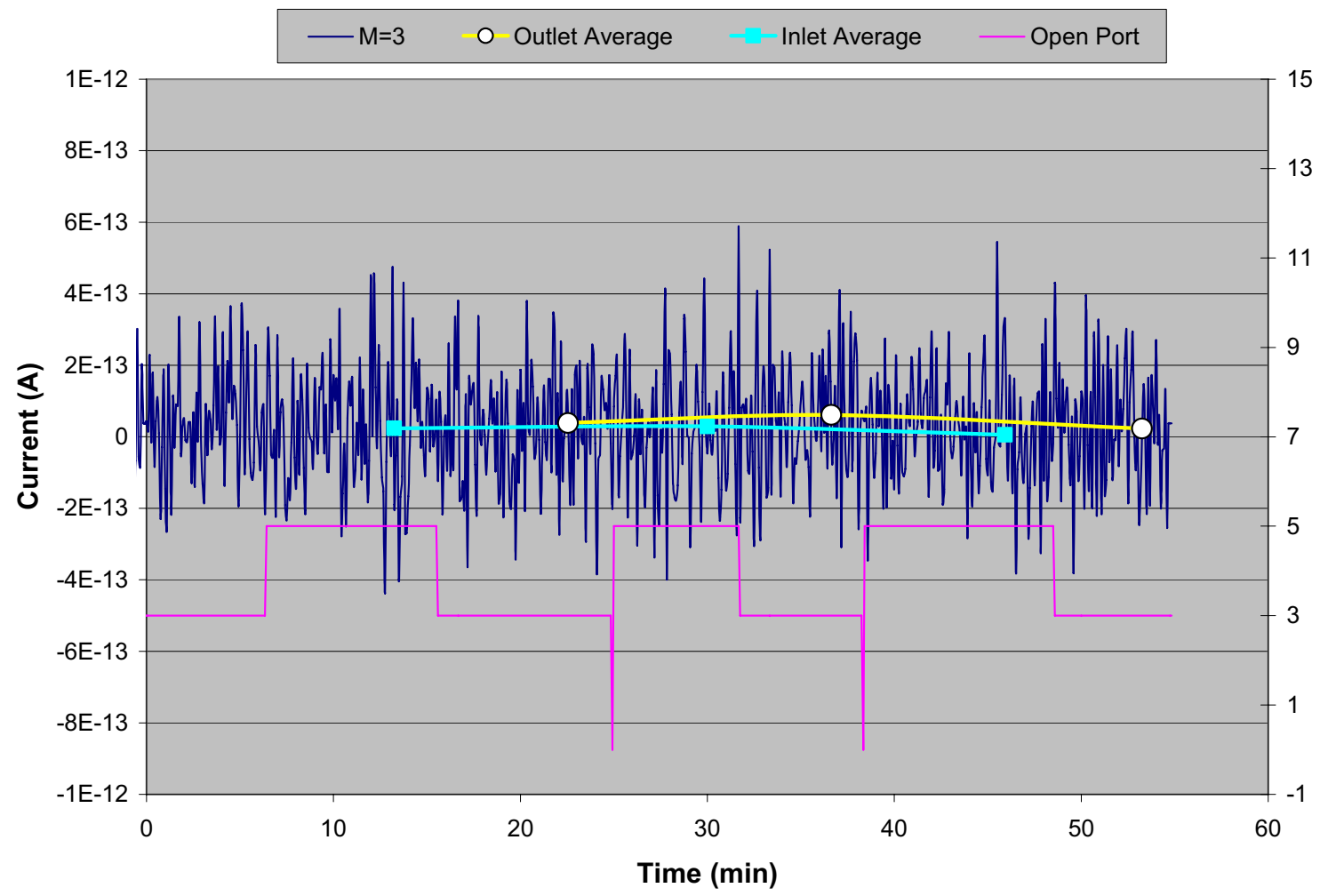

Figure 10. Mass-3 data for the $10 \mathrm{sccm}$ experiment. 
Hydrogen data (mass $=2$ ) are shown in Figure 11. It appears that $\mathrm{H}_{2}$ is richer at the outlet than at the inlet for most of the test. ${ }^{\mathrm{b}} \mathrm{H}_{2}$ ingress is certainly the case in experiments at higher temperatures and longer tube lengths, as will be shown below.

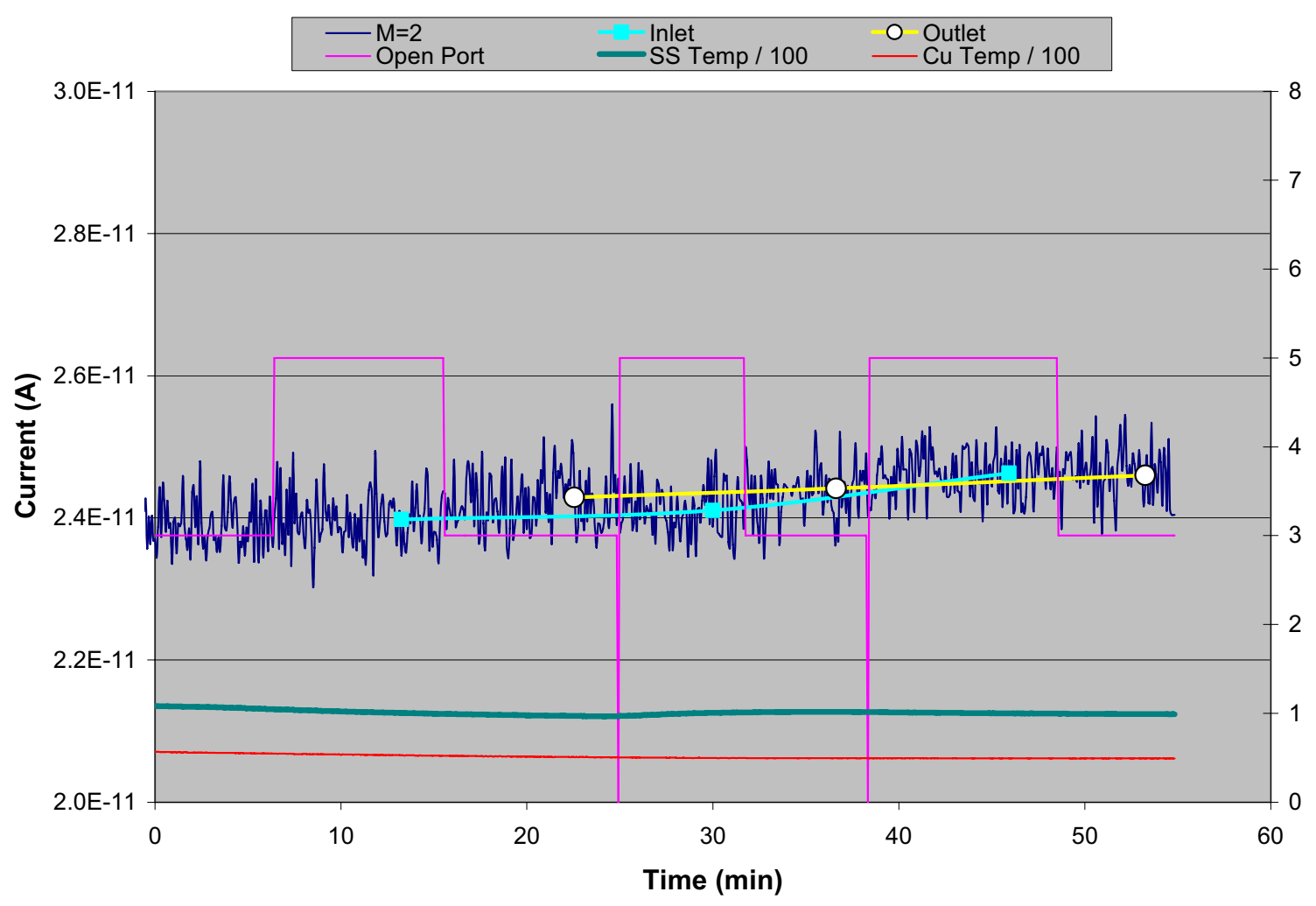

Figure 11. Mass-2 data for the $10 \mathrm{sccm}$ experiment.

The mass-19 data for HDO are curious. These data are in Figure 12. Two aspects are worthy of note. One is that there is a gradual rise in the mass-19 signal over the course of the experiment. The other is that the data points all lie essentially on the same curve. The latter point is evidence that there is little or no production or loss of vapor phase HDO in the experiment length. The general rise over the test duration is essentially the same fractional rise as is evident for the mass-2 data in Figure 11. ${ }^{\mathrm{b}}$ The supposition is that the HDO is actually generated in the quadropole head rather than in the experiment.

The change in the mass-20 signal is also interesting. These data are shown in Figure 13. There is the appearance of some production of $\mathrm{D}_{2} \mathrm{O}$ in the test section, increasing as the test progressed. The amplitude ratio for the right-most pair of data points in Figure 11 is 1.081. From the scaling of the intensity of the water peak (2.09E-10A for $1.58 \%$ water vapor), obtained by sampling room air at known humidity, it was found that the increment in the last pair of points, $6.96 \mathrm{E}-14 \mathrm{~A}$, if real, would mean the gas stream would

\footnotetext{
${ }^{b}$ Note that the general upward drift of the mass-2 signal over the course of a test is characteristic of the mass spectrometer and is believed due to differential pumping speeds for gases of various weights by the turbomolecular pump evacuating the ion chamber.
} 


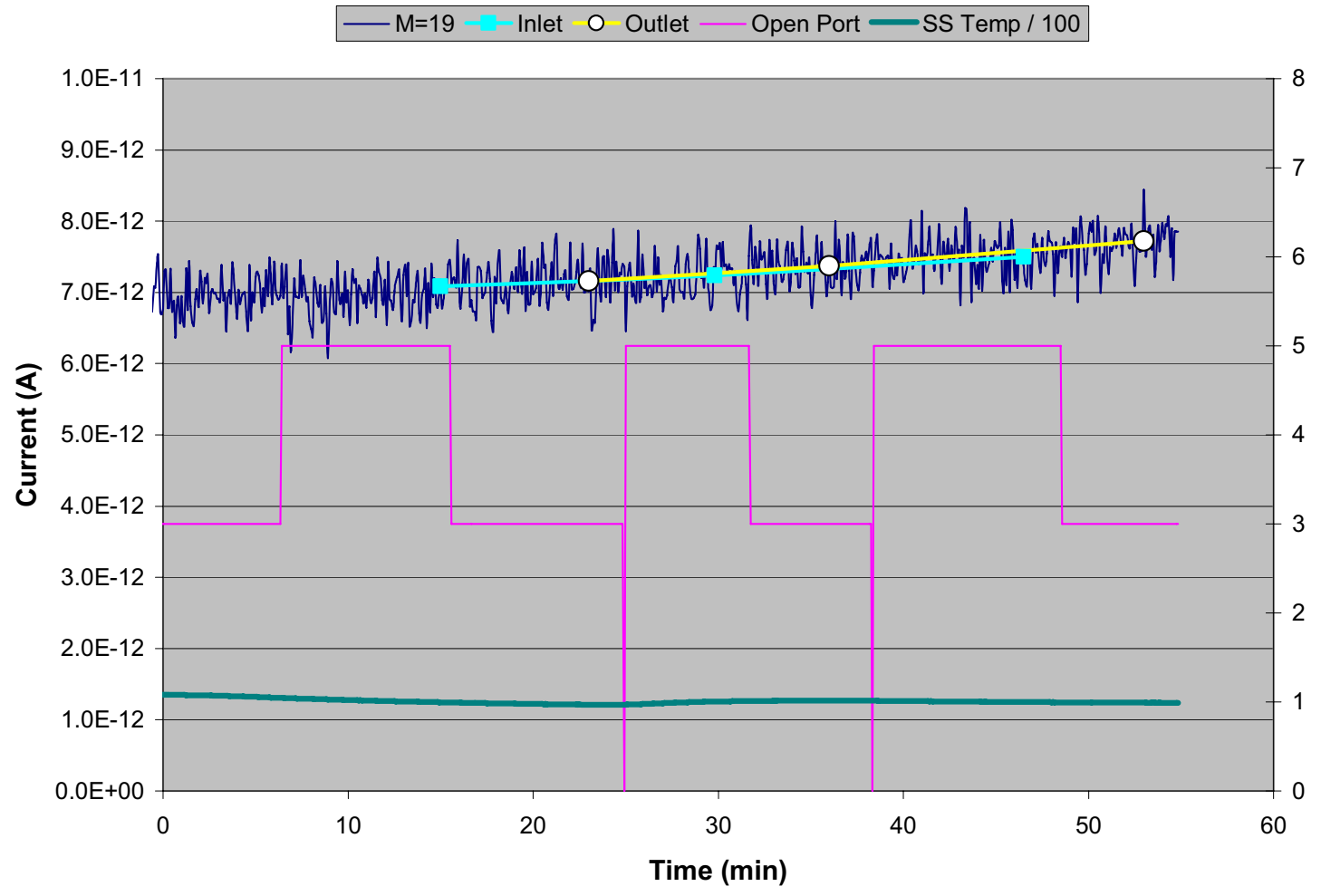

Figure 12. Mass-19 data for the 10 -sccm experiment.

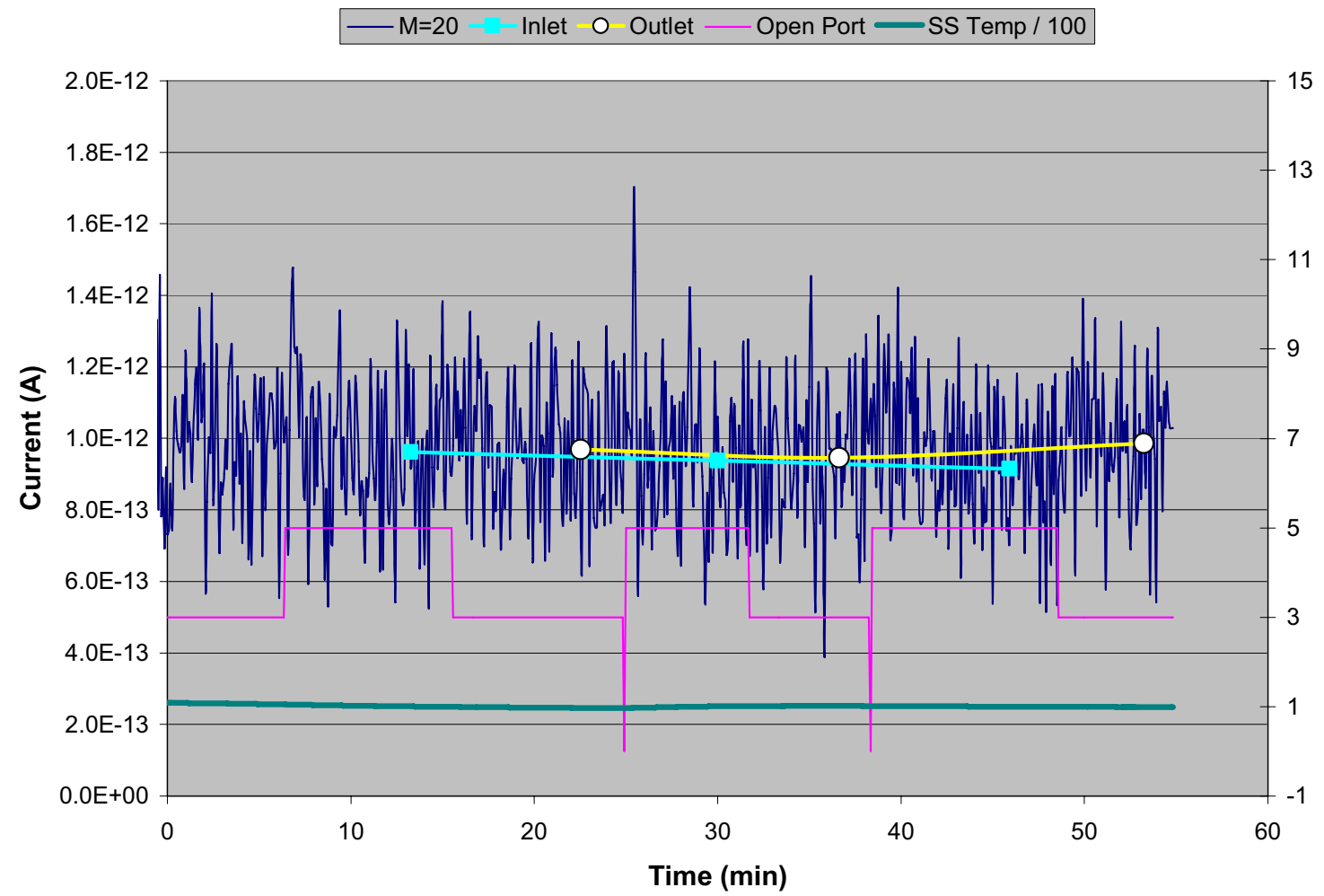

Figure 13. Mass-20 signal for the 10-sccm experiment. 
gain $\mathrm{D}_{2} \mathrm{O}$ in the amount of $5.24 \mathrm{ppm}$ or about 32 times the $\mathrm{D}_{2}$ input to the experiment. That seems highly unlikely. There could be a small increase over time as the $\mathrm{D}_{2} \mathrm{O}$ uptake on the walls of the tubing due to isotopic exchange reached saturation. However, looking at Figure 7, the $\mathrm{D}_{2}$ loss is at most a few ppb and that could not possibly be seen in Figure 13. Further, the difference in the signals is only $4.3 \%$ of the standard deviation of the data at most. One is thus left to suppose that the apparent change in mass-20 data must be due to random statistical fluctuation. Further, as will be seen later, there was no such signal difference in the 25 -sccm test.

\section{5-sccm Test}

The tests at $25 \mathrm{sccm} \mathrm{N} \mathrm{N}_{2}$ flow rate were similar to each other and to those at $10 \mathrm{sccm}$. Figure 14 shows the mass- 4 variation in one of those. As in the 10 -sccm test (Figure 6) the initial burst of $\mathrm{D}_{2}$ is seen in Figure 14, first as it passes the experiment inlet and then again as it passes the outlet. Here the second peak is $22 \%$ lower than the first. This is only a little different from the $19 \%$ seen in Figure 7 sampling times. Again, the loss is believed to be uptake by oxidation on dry walls. Once that reservoir is filled, there is very little difference between inlet and outlet $\mathrm{D}_{2}$ concentrations as evidenced by their co-linearity The mass-3 data (Figure 15) and the Mass-20 data (Figure 16) likewise show very good co-linearity, a further indication that there is little if any activity of the $\mathrm{D}_{2}$ with system walls after the initial uptake. The mass- 20 averages decline slightly with time and rising temperature of the model capsule. The inlet values drop 5\%, and the outlet values drop 3\%. The downward trends are similar to those seen in Figure 13, though much less pronounced. The higher flow rate and lower concentration of $\mathrm{D}_{2} \mathrm{O}$ in Figure 16 relative to Figure 15 are consistent with that result. The fact that temperature in Figure 13 is generally falling while in Figure 16 it is rising leads to the conclusion that the drifts are more dependent on time than on temperature and may reflect the evacuation of water (mass 18) from the system. The mass-19 signals (Figure 17) are climbing, but this is in response to the rise in mass-2 (Figure 18) as it was in the 10-sccm test. It appears in Figure 18 that $\mathrm{H}_{2}$ may be exiting the experiment, but this is believed to be only a statistical anomaly.
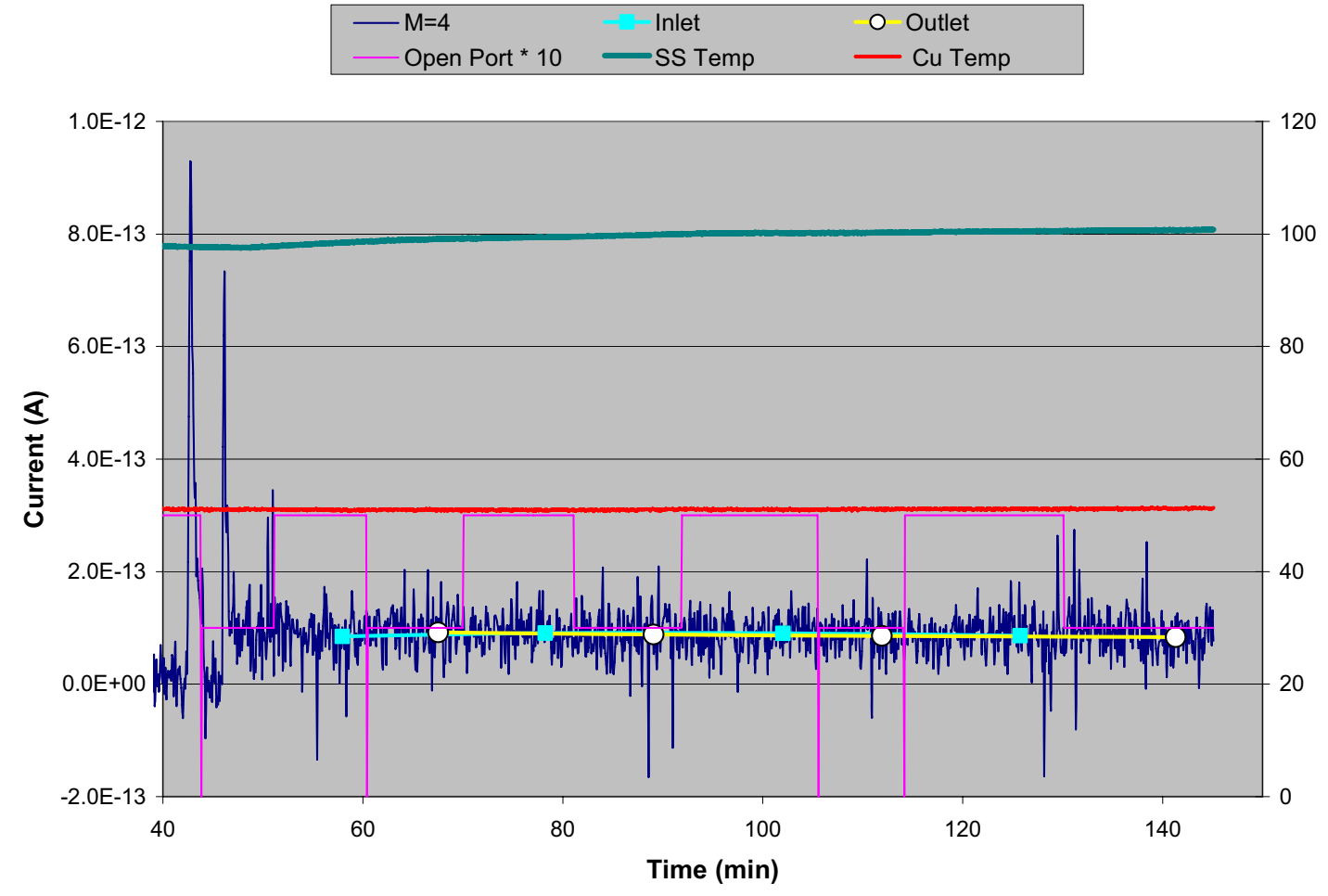

Figure 14. Mass-4 data for the $25 \mathrm{sccm}$ experiment. 


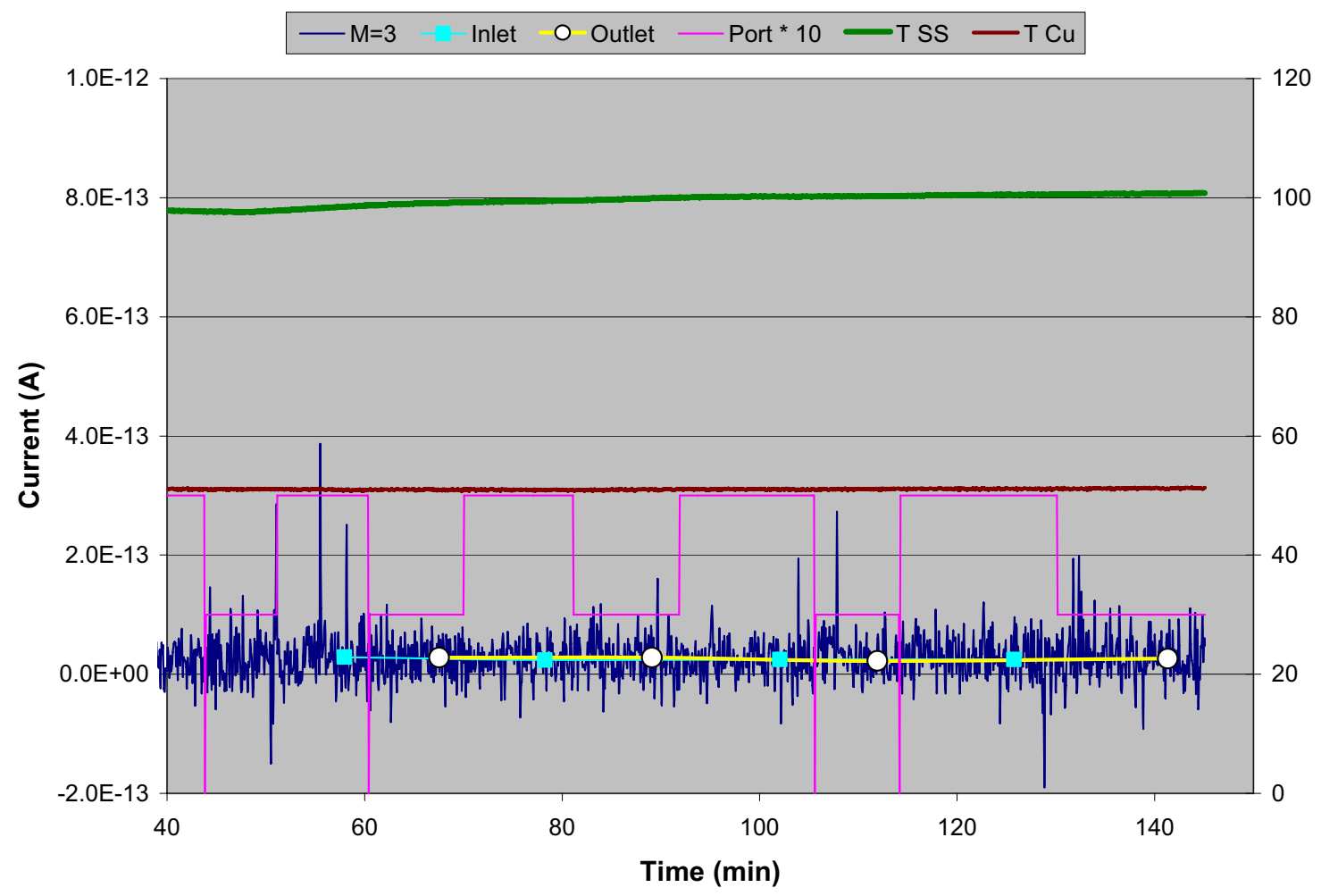

Figure 15. Mass-3 data from the 25-sccm experiment.

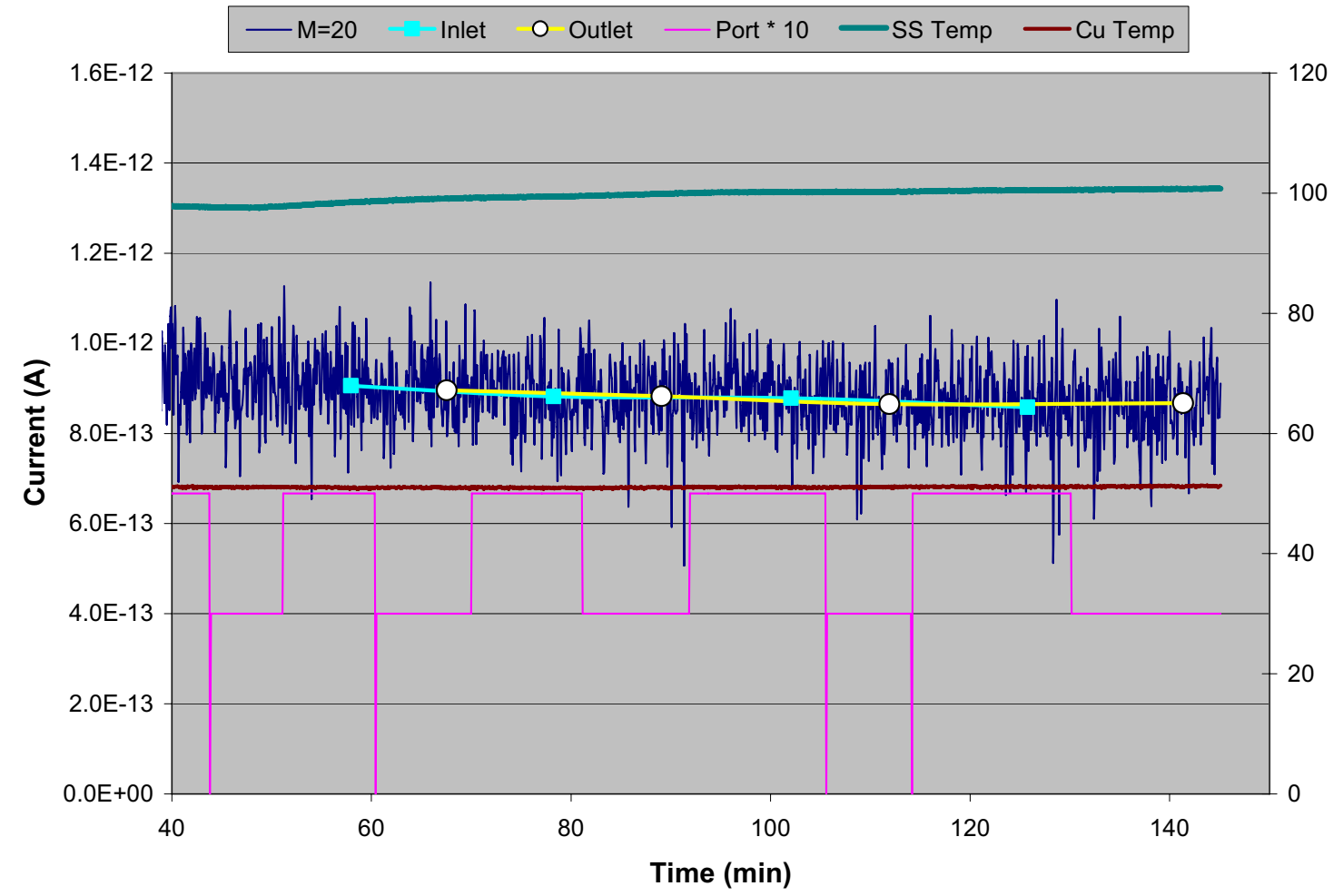

Figure 16. Mass-20 data from the 25 -sccm experiment. 


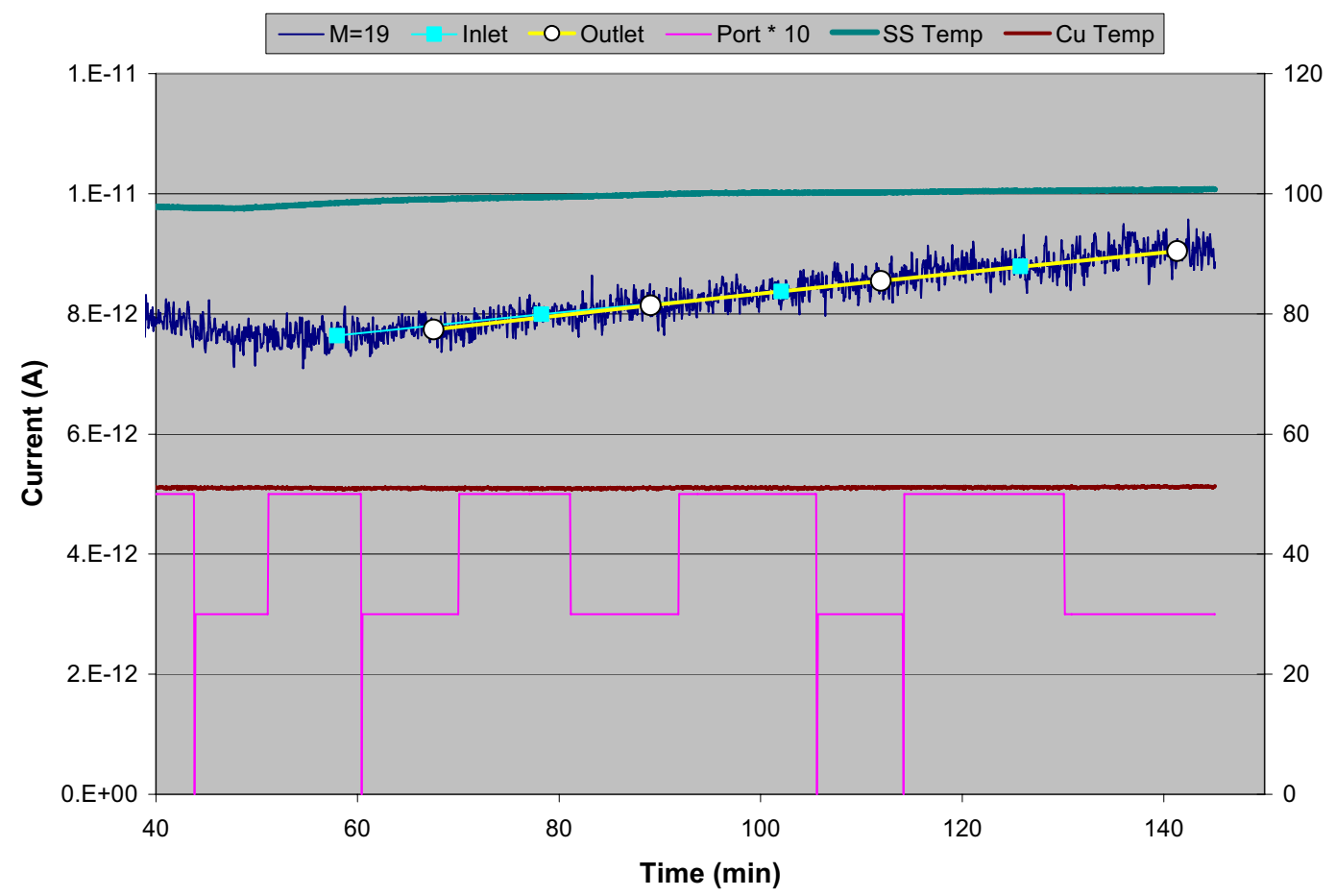

Figure 17. Mass- 19 data from the $25-\mathrm{sccm}$ experiment.

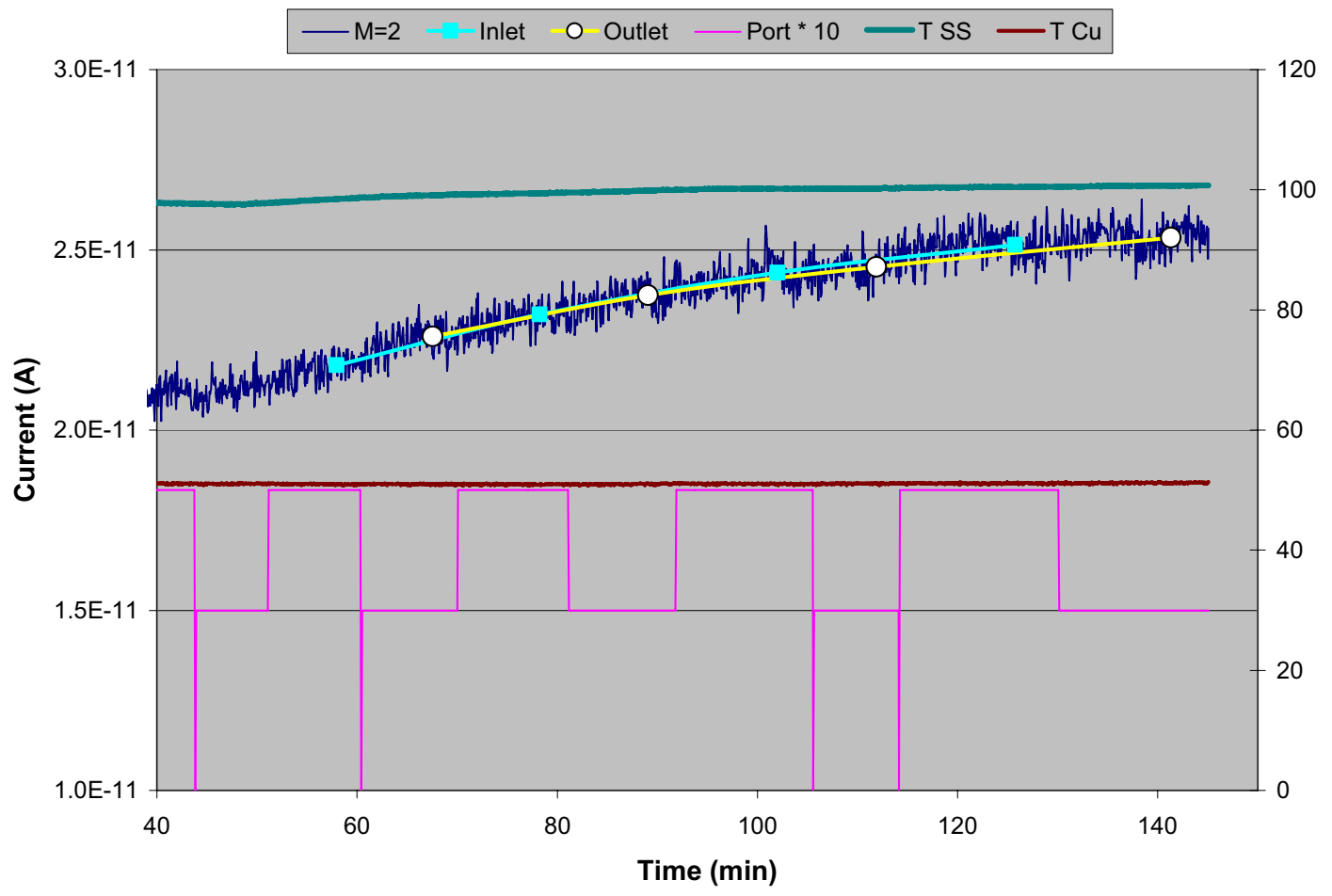

Figure 18. Mass-2 data from the 25 -sccm experiment. 


\section{Other Data}

Before the engineering model tests were conducted, the experimental apparatus was used to explore transport and conversion issues in heated copper and stainless steel tubes. The general observation was that $\mathrm{D}_{2}$ loss and $\mathrm{H}_{2}$ gain are significant at temperatures around $500^{\circ} \mathrm{C}$, but they are relatively insignificant at the temperatures we are speaking of for TMIST-2. This is exemplified by Figure 19 which shows the influence of temperature on the loss of $\mathrm{D}_{2}$ to the walls of an $80 \mathrm{ft}$ long 1/8-inch stainless steel tube that had an inlet $\mathrm{D}_{2}$ concentration of $126 \mathrm{ppb}$ in $\mathrm{N}_{2}$ carrier gas that was flowing at $10 \mathrm{sccm}$.

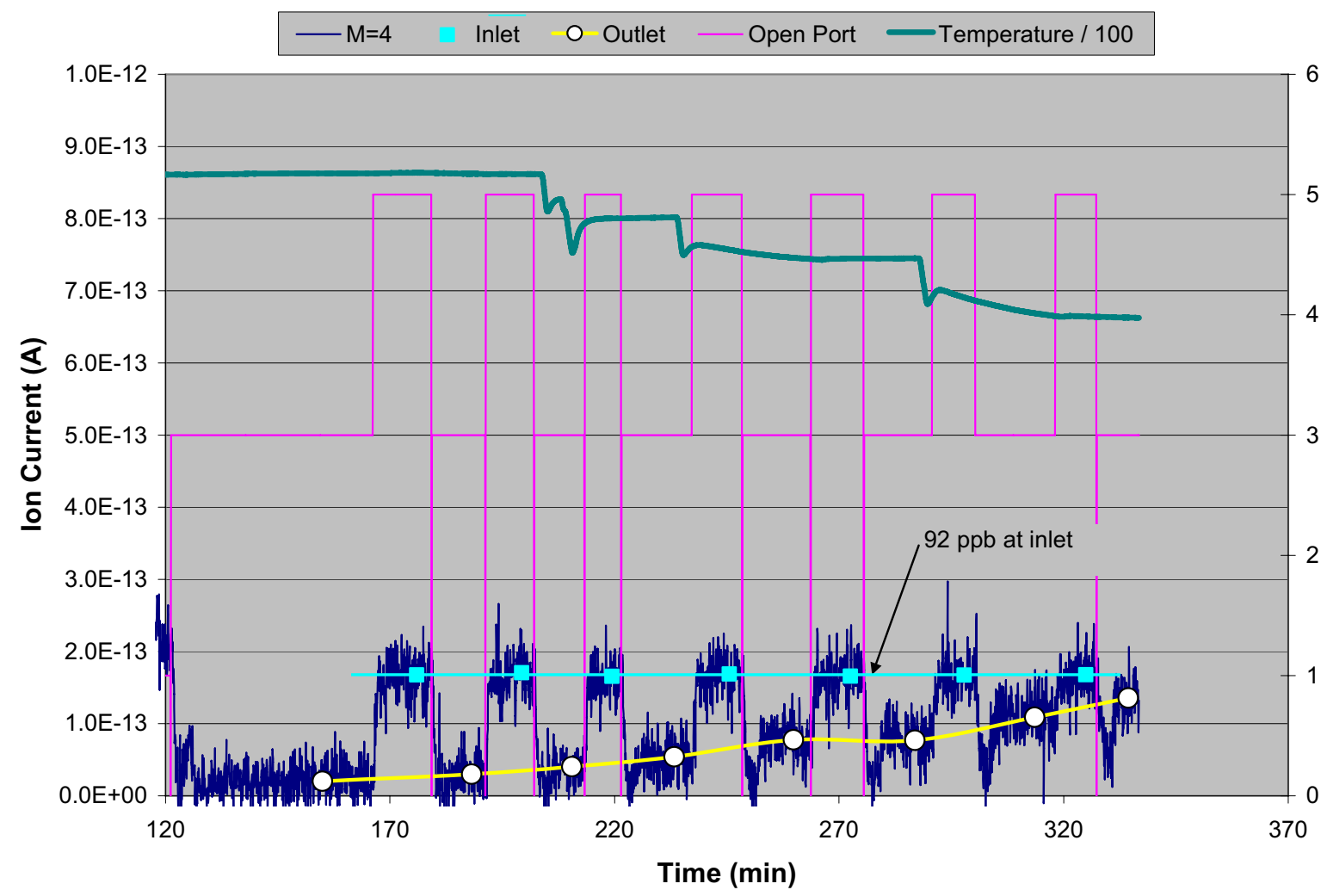

Figure 19. Test data for $\mathrm{D}_{2}$ in an 80 - $\mathrm{ft}$ long $1 / 8$-inch stainless steel tube with the carrier gas flowing at 10 sccm.

To make use of these data, the reduction of $\mathrm{D}_{2}$ concentration may be phenomenologically described by the expression

$$
\frac{C}{C_{o}}=\exp \left(-\frac{K L}{R Q}\right)
$$

where $C$ is the $\mathrm{D}_{2}$ concentration, $C_{o}$ is its value at the tube entrance, $K$ is a rate coefficient, $L$ is the length of the tube, $\mathrm{R}$ is the tube radius, and $Q$ is the volumetric flow rate of the gas through the system. This expression has the range $(0,1)$, and it is based on the expectation that the $C / C_{o}$ ratio will decrease with greater tube length and increase with greater tube radius (lower surface-to-volume ratio) and faster flow (lower residence time). The rate coefficient $K$ can be found from (2) as 


$$
K=-\frac{R Q}{L} \ln \left(\frac{C}{C_{o}}\right)
$$

It will be assumed that the rate coefficient $K$ is an Arrhenius function of the form

$$
K=A \exp \left(-\frac{E}{\mathfrak{R} T}\right)
$$

where $E$ is an activation energy and $\mathfrak{R}$ is the gas constant.

Figure 20 shows the rate coefficient expressed by (3) with $R=0.0275$ inches, $Q=0.610 \mathrm{in}^{3} / \mathrm{min}$ (STP), $L=960$ inches, and $C / C_{o}$ from the data in Figure 17. It is found from the fit line shown that $A=1.105$ $\mathrm{in}^{3} / \mathrm{min}$ and $E=68,562 \mathrm{~J} / \mathrm{mole}$. When these values are used in (2) with the TMIST-2 parameters of $R=$ 0.181 inches, $Q=1.83 \mathrm{in}^{3} / \mathrm{min}(30 \mathrm{sccm})$, and $L=11$ inches, the value of $C / C_{o}$ calculated is 0.999999991 . For the lower flow rate of $0.61 \mathrm{in}^{3} / \mathrm{min}(10 \mathrm{sccm})$, the value wasn't much different, 0.999999974 . If $L$ is changed to 1200 inches, the conversion numbers drop slightly to 0.999999044 and 0.999997132 , respectively. These numbers are consistent with the observations made in these tests that except for the initial wall loading there was effectively no $\mathrm{D}_{2}$ lost through the model experiment.

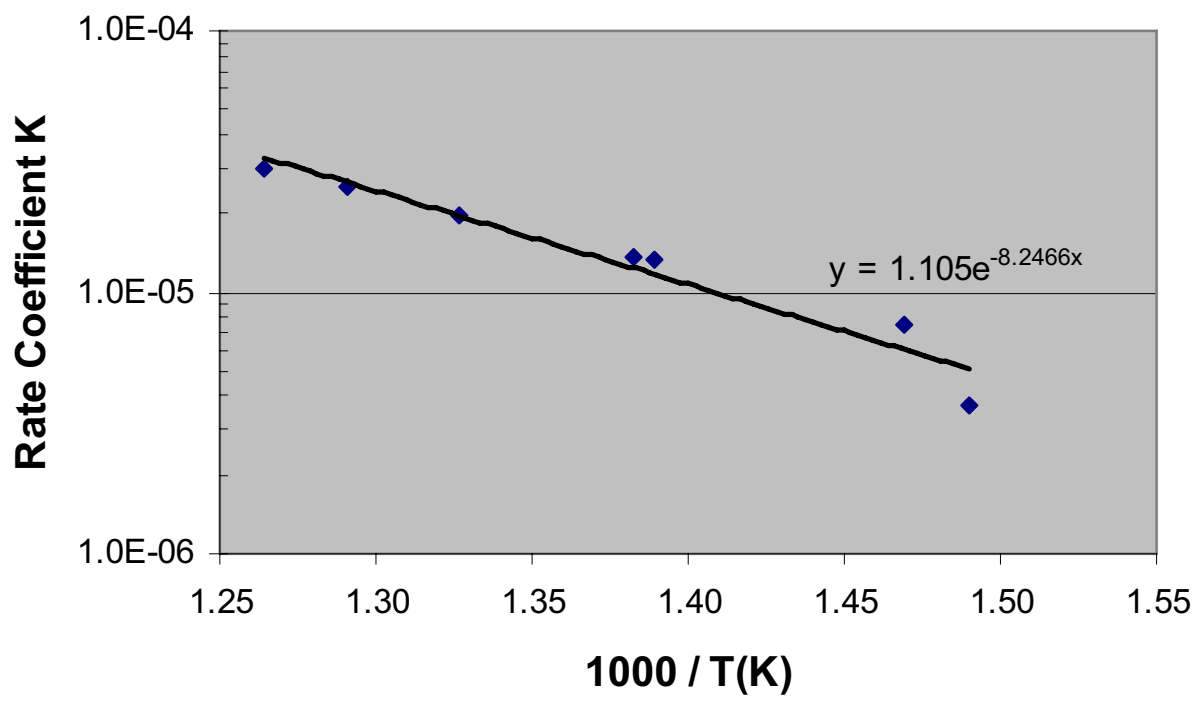

Figure 20. Arrhenius plot of the rate coefficient expressed by Equation (3).

These experiments and others of similar nature were unsuccessful in observing any $\mathrm{D}_{2} \mathrm{O}$ coming from the $\mathrm{CuO}$ oxidizer operated at $360^{\circ} \mathrm{C}$. Even when the oxidizer was operated at $220^{\circ} \mathrm{C}$ and only about half of the $\mathrm{D}_{2}$ going into it was lost, there was no detectable mass-20 signal above noise. It is possible that all the oxidized deuterium was taken up on the walls of the oxidizer chamber. A more likely reason is that the oxidized $\mathrm{D}_{2}$ was indistinguishable against the relatively strong background at mass 20 . Variations in the mass-19 and mass-20 signals in these experiments are believed to be due to activity in the quadropole head of the mass spectrometer and not in the experiment. 
The conversion rate of $\mathrm{T}_{2}$ to HTO in a closed system, more highly oxidized but otherwise somewhat similar to the one used here, was found in previous experiments ${ }^{4}$ to be given by

$$
\frac{\mathrm{dC}_{\mathrm{HTO}}}{\mathrm{dt}}=1.987 \frac{\mathrm{S}}{\mathrm{V}} \exp \left(-\frac{62,844}{\mathrm{RT}}\right) \mathrm{C}_{\mathrm{HT}}
$$

If one substitutes TMIST-2 values of $2 / \mathrm{R}=28.22 \mathrm{in}^{-1}$ for $\mathrm{S} / \mathrm{V}$ and $372 \mathrm{~K}$ for $\mathrm{T}$ in that experiment, one finds that the conversion rate to water would have a time constant of 4.3 months. The conversion fraction with a 6-minute transit time would be 3.19E-05, higher than the fraction just computed above but consistent with the difference in the state of oxidation of the tubing. This is again indicative of very little conversion in the present experiments or on surfaces other than the liner specimen in TMIST 2 . The conversion on the liner would be considerably less than $1 \%$.

\section{CONCLUSIONS}

When the deuterium was first introduced into the test section that had been heated and dried, there was an initial period of about 10 to 15 minutes during which there was an observable loss of $\mathrm{D}_{2}$ from the carrier gas. This loss amounted to about $16 \%$ for both the 10 -sccm test and the 25 -sccm test. The 25 -sccm test had only $66 \mathrm{ppb} \mathrm{D}_{2}$ whereas the 10 -sccm test had $165 \mathrm{ppb} \mathrm{D}_{2}$. This loss of $\mathrm{D}_{2}$ in the experiment is to the copper tubing, not to the stainless steel components simulating the TMIST-2 capsule.

There appeared to be virtually no loss of $\mathrm{D}_{2}$ or gain of HD in either the 10 -sccm test or in the 25 -sccm test after that initial loss transient.

It appears that there should be no problem seeing the elemental tritium that permeates through the liner specimens in TMIST-2 once the initial uptake transient is over. Given the similitude between the model experiment and the TMIST-2 experiment, that transient should only last a few minutes if the permeating tritium current is on the order of $10^{13} \mathrm{~T}_{2} / \mathrm{s}$, the range of the experiments reported here. It is expected that the initial transient will take proportionately longer to saturate to the extent that the tritium concentration in the TMIST-2 sweep gas is lower.

It is not known how much of the permeating tritium will appear as oxide. To the extent that the tritium comes through the stainless steel liner as elemental gas and is only oxidized on other surfaces, this experiment would imply that not much will be converted to oxide. That would also be the conclusion from earlier studies where conversion rates were observed to be high at elevated temperatures but low at temperatures anticipated for TMIST-2. No conclusions can be drawn from this work on what will become of tritium emerging from the stainless steel liner as $\mathrm{T}_{2} \mathrm{O}$ or HTO.

It was not practical to redo the present experiment using $\mathrm{He}$ as the carrier gas because the majority carrier gas tends to mask peaks on either side unless they are near the same order of magnitude in concentration. A mass-3 peak at a few ppb would be invisible against the He peak.

\section{REFERENCES}

1. Tritium Technology Program, "Functional Requirements for the TPBAR Materials Irradiation Separate-Effects Test - 2 (TMIST-2), TTP-1-178, Rev. 0. August 7, 2007, Pacific Northwest National Laboratory, Richland, Washington. 
2. Tritium Technology Program Procedure, "Test Plan for TPBAR Materials Irradiation SeparateEffects Tests (TMIST), TTP-3-026, Rev. 1, October 16, 2007, Pacific Northwest National Laboratory, Richland, Washington.

3. G. R. Longhurst and J. Cleaver, 2007, "Interactions of Hydrogen Isotopes and Oxides with Metal Tubes," 8th International Conference on Tritium Science and Technology, September 16-21, 2007, Rochester, New York; to be published in Fusion Science and Technology.

4. G. R. Longhurst, 2007, “Tritiated Water Interaction with Stainless Steel,” INL/EXT-07-12584, Idaho National Laboratory, Idaho Falls, Idaho. 